\title{
The Evolution of Complex Organs
}

\section{T. Ryan Gregory}

Published online: 10 October 2008

(C) Springer Science + Business Media, LLC 2008 yielded tremendous advances in the understanding of life's complexities and the historical origins thereof.

There was a time when natural processes capable of producing complex biological features were deemed inconceivable, leading to the conclusion that these, like human artifacts, must be the products of intelligent agency (e.g., Paley 1802). Beginning with Darwin's (1859) description of natural selection, and expanding considerably upon it in the 150 years since, the science of evolutionary biology has assembled a theoretical framework capable of explaining how complex features can arise naturally over time. Still, while few nonspecialists have trouble acknowledging small-scale evolutionary processes such as the evolution of antibiotic resistance within populations of bacteria, they often remain uncertain as to how similar mechanisms could account for complex structures such as eyes or wings (Ayala 2007; Scott and Matzke 2007).

This article provides a general overview of the various processes that play a role in the evolution of complex biological systems. The classic exemplars of organ complexity, eyes, are then used as a case study to illustrate these general mechanisms. Although it is not possible to deliver a comprehensive discussion of eye evolution within the confines of this paper, an extensive (but by no means exhaustive) reference list is provided in order to facilitate further study of the subject, as well as to highlight the rich scientific literature that exists on this topic but which may be largely unknown outside professional biological circles. Finally, some common misconceptions regarding the evolution of complex features are discussed.

\section{How Complex Organs Evolve}

The concept of "complexity" is anything but simple. In fact, many technical definitions are in use in mathematics, 
computer science, and other disciplines. Means of quantifying complexity have been developed in evolutionary biology as well, as have methods for assessing trends involving changes in complexity through deep time (for review, see Gregory 2008a). This paper is not about complexity per se, but about the evolution of complex organs: biological structures with several intricately interacting parts that function in a sophisticated manner, the eye being the primary example discussed. Complexity as defined in this intuitive sense is not restricted to organs - it also applies to biochemical, subcellular, behavioral, and other biological systems. On the other hand, not all functional systems are complex, nor is complexity inherently advantageous or inevitable as efficiency can readily trump a convoluted arrangement.

Fundamentally, evolutionary explanations for the origin of biological features, complex or otherwise, are based on the assumption of continuity. That is to say, there is an unbroken chain of ancestry and descent linking modern organisms with earlier species that lived long ago. In order to account for the existence of complex organs as they are observed today, it is necessary to provide an account of how these could have arisen, without breaks or inexplicable leaps, from less complex antecedents. The following sections outline various processes that, taken together, are considered by evolutionary biologists to meet this requirement.

\section{Direct Adaptation by Natural Selection}

Darwin famously noted in 1859 (p.189) that "if it could be demonstrated that any complex organ existed, which could not possibly have been formed by numerous, successive, slight modifications, my theory would absolutely break down." It should be understood that the "theory" in question is not the notion that species are related by descent; rather, it is the proposal that the mechanism responsible for evolution is natural selection acting gradually on minor heritable differences (see Gregory 2008b). There is absolutely no scientific disagreement as to whether natural selection occurs, as it can be observed in both experimental and natural populations; the question is whether this process alone can result in the emergence of complex organs such as eyes.

The process of gradual, stepwise adaptive change emphasized (though not exclusively so) by Darwin has been called "direct evolution" and can be further subdivided into two major types (Thornhill and Ussery 2000):

1. Serial direct evolution. The simplest form of adaptive evolution, which proceeds step by step from $\mathrm{A}_{1} \rightarrow \mathrm{A}_{2} \rightarrow$ $A_{3} \rightarrow A_{4}$ and involves gradual change along a single axis (i.e., each step serves the same function but effectiveness increases from $A_{1}$ to $A_{4}$ ). A second series of changes may take place in addition to the first, but in this scenario it would be only after the first series of changes ended.
2. Parallel direct evolution. A slightly more complicated form of direct adaptation in which changes occur at the same time in more than one component, as in $A_{1} / B_{1} \rightarrow$ $A_{2} / B_{2} \rightarrow A_{3} / B_{3} \rightarrow A_{4} / B_{4}$. In this case, no single component becomes greatly modified before the others do.

Under serial direct evolution, each change that occurs is small, involves only one component of a particular system, and, in principle, is reversible. As a result, serial direct evolution does not produce organs with indivisibly integrated components. Parallel direct evolution, on the other hand, can produce a moderate interdependence of parts because these change in concert with one another. Neither serial nor parallel direct evolution necessarily leads to an increase in complexity, and in terms of highly complex organs, the most important contribution made by direct adaptive evolution probably relates to refinements of particular functions through the modification of a few components. Thus, direct evolution by itself is not sufficient to properly account for the evolution of highly complex and integrated organs, and as such, additional processes are necessary.

\section{Indirect Evolution}

Direct adaptive evolution by natural selection has, since it was first proposed, been subject to criticism by those who disagree that it is sufficient to explain the origin of complex biological features. In Darwin's own time, opponents began listing features of organisms for which incipient or intermediate stages seem unlikely to have been functional and which therefore could not have been be shaped incrementally by natural selection (e.g., Mivart 1871). Darwin (1872) responded by pointing to examples of organs of "intermediate" complexity that did, or indeed still do, exist in other species. ${ }^{1}$ Nevertheless, there are legitimate reasons to expect direct gradual evolution along a single axis to be incapable of producing complex adaptations composed of tightly interacting parts. As a result, evolutionary biologists (including Darwin) have long pointed out the importance of indirect routes by which complex organs and systems can evolve.

A recent analysis of the evolution of two hormone-receptor pairs provides an illustration of the basic concept of indirect evolution (Adami 2006; Bridgham et al. 2006). The close match between a hormone and the receptor to which it binds has been considered analogous to that between a "lock and key," both of which are required for the system to function.

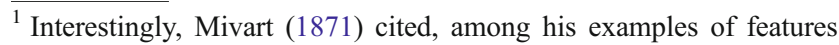
that he presumed would be very unlikely to evolve gradually, the appearance of two eyes on one side of the head among flounders and the feeding structures of baleen whales - both of which have been discussed recently in light of evidence indicating that intermediate forms did indeed occur (Deméré et al. 2008; Friedman 2008; Janvier 2008; Zimmer 2008).
} 
The challenge, as with more complex biological features, is to explain how such a system evolved through intermediates to its current, integrated state, given that it is not reasonable to hypothesize that the components arose together instantaneously by mutation.

In vertebrates, the stress hormone cortisol activates the glucocorticoid receptor, which is involved in regulating metabolism and immunity whereas a related receptor, the mineralocorticoid receptor, is activated by aldosterone to regulate electrolyte homeostasis (in abstract terms $\mathrm{A}+\mathrm{B} \rightarrow \mathrm{X}$ whereas $\mathrm{C}+\mathrm{D} \rightarrow \mathrm{Y}$ ). This specificity is important, as activation of the wrong receptor would be very detrimental to the organism (it would be a problem if $\mathrm{A}+\mathrm{D} \rightarrow \mathrm{Y}$; Adami 2006). Having the two receptors activated separately is also beneficial as it allows metabolism to be regulated independently of electrolytes, for example (Bridgham et al. 2006).
Phylogenetic analyses suggest that the two receptors are derived from an ancestral gene that duplicated about 450 million years ago (Mya). Aldosterone, by contrast, is found only in tetrapods and, therefore, evolved long after the origin of the two receptors (Fig. 1A). The question is, how could these receptors become specific for different hormones when one of the hormones did not yet exist?

In order to address this question, Bridgham et al. (2006) used phylogenetic approaches to reconstruct the ancestral corticoid receptor and found that it would have been sensitive to cortisol, aldosterone (had it existed), and another hormone known as 11-deoxycorticosterone. The difference between this early receptor and the modern glucocorticoid receptor, which does not bind aldosterone, lies in amino acid changes caused by two mutations - either one of these changes alone makes the receptor insensitive to cortisol, but both

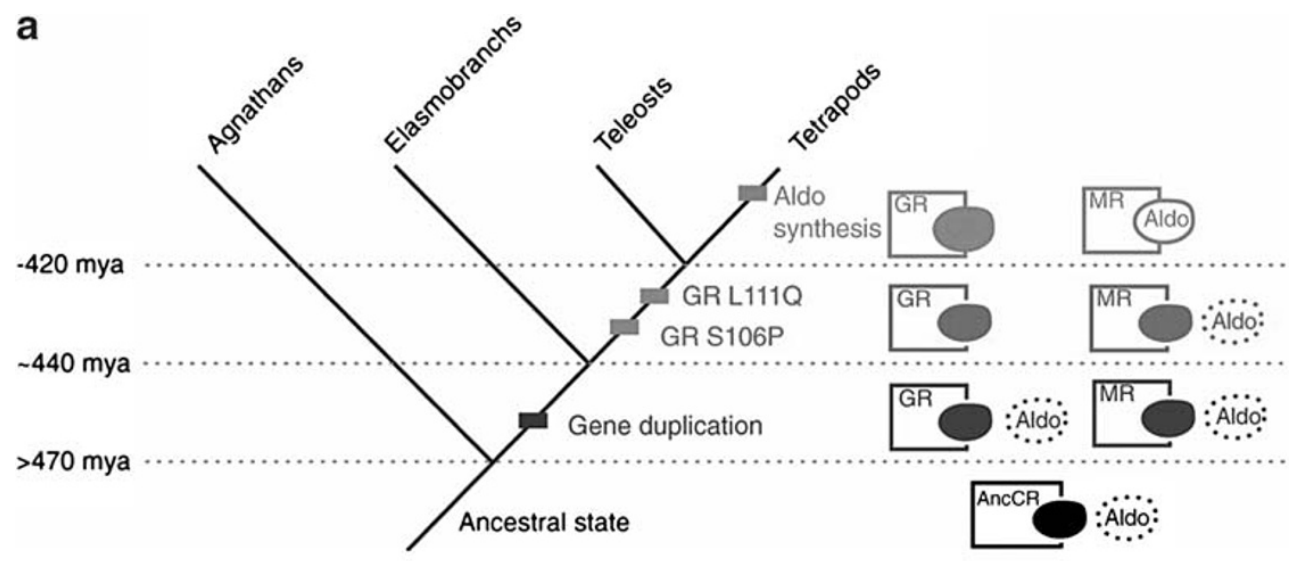

b
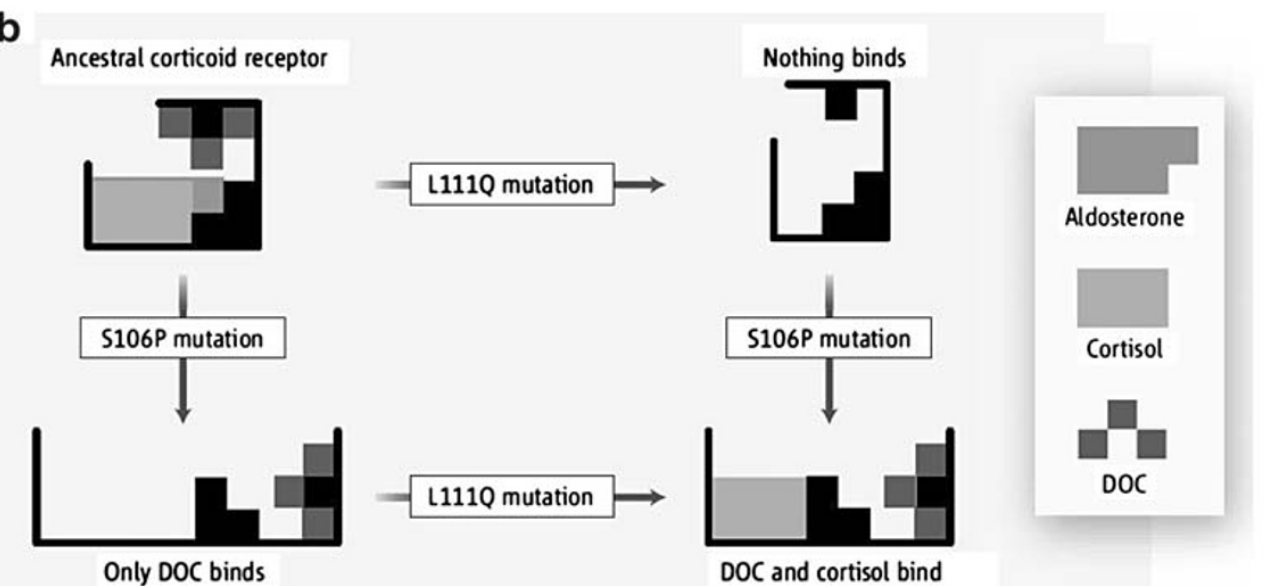

Fig. 1 Indirect evolution of two hormone-receptor pairs. A Steps involved in the origin and evolution of the glucocorticoid receptor $(G R)$ which is sensitive to cortisol and the mineralocorticoid receptor $(M R)$ which is sensitive to aldosterone. The two receptors are derived from a gene for a single ancestral receptor $(A n c C R)$ which duplicated about 450 Mya. Later, two mutations occurred in the GR receptor that made it insensitive to aldosterone. Aldosterone (Aldo) did not evolve until much later (represented by a dotted circle before it arises) but was able to bind to the MR, which had retained a form close to the ancestral receptor because a third hormone similar to aldosterone formerly

activated it. From Bridgham et al. (2006), reproduced by permission of the American Association for the Advancement of Science. B The two mutations required to make the GR insensitive to aldosterone ( $L 111 Q$ and $S 106 P$ ) both make the hormone insensitive to cortisol if they occur by themselves, and it is unlikely that both arose simultaneously. This apparent problem can be explained by the fact that a third hormone, 11deoxycorticosterone $(D O C)$ can still bind; therefore, the receptor can still be functional (in a different manner) if the S106P mutation occurs first. From Adami (2006), reproduced by permission of the American Association for the Advancement of Science 
together make it sensitive to cortisol and insensitive to aldosterone. It is unlikely that both mutations would occur simultaneously, but Bridgham et al. (2006) found that one of the mutations retained sensitivity to 11-deoxycorticosterone, meaning that this intermediate step would still be functional, though in a different way, and could still have been favored before the second mutation occurred (Fig. 1B). Meanwhile, selection acting to maintain specificity for a different hormone that was structurally similar to aldosterone meant that once aldosterone arose, it could bind to the mineralocorticoid receptor which remained similar to the ancestral form (a process Bridgham et al. 2006 call "molecular exploitation"; Fig. 1A).

In short, even though they are now indivisible, the two hormone-receptor pairs could have evolved through a stepwise series favored at each stage by natural selection, but the steps were not direct. The process involved gene duplication, the input of a third hormone, and shifts in function. Similar processes may operate generally in the evolution of complex proteins in a manner that is readily explained by modern evolutionary theory (see Lynch 2005 for a technical discussion). These and other indirect evolutionary processes are also involved in the evolution of complex organs and their components, and are discussed in more detail in the following sections. It is important to note that most complex organ evolution probably involves processes from various parts of the direct-indirect evolutionary continuum.

\section{Exaptation}

The notion of functional shifts is an old one in evolutionary biology, having been considered "an extremely important means of transition" by Darwin (1872, p.147). The general process has been known by many names: "co-option," "adoption from a different function," "recruitment" (mostly in reference to genes), or, in an outmoded term a little too suggestive of teleology, "preadaptation" (e.g., Gould and Vrba 1982; Arnold 1994; Thornhill and Ussery 2000; McLennan 2008). However, the basic concept became much more broadly appreciated when it was granted a specific name with a clearer definition: "exaptation" (Gould and Vrba 1982).

The term "exaptation" derives from ex + aptus, meaning fit (aptus) by reason of (ex) existing form, as contrasted with adaptation, which derives from ad (towards) + aptus (fit). So, whereas an adaptation is the product of natural selection favoring variants on the basis of, and gradually improving, the current function, an exaptation is a feature that arose for some other reason and subsequently acquired its current function. Designating a feature as an exaptation presumes some knowledge regarding ancestral function (or lack thereof) such that it can be shown to have differed from the current role. Data bearing on this issue can be obtained using fossils and phylogenetic inference (e.g., Arnold 1994). The process- es of adaptation and exaptation are not entirely separate, however, because once a functional shift occurs natural selection may modify the feature with regard to its new role in a process of "secondary adaptation" (Gould and Vrba 1982; Fig. 2). Most complex organs are likely to represent a mixture of primary adaptations, exaptations, and secondary adaptations.

The evolution of wings provides one of the classic examples of exaptation and secondary adaptation. As has been pointed out many times, a rudimentary version of a wing would not be useful in flight because it would be unable to generate sufficient lift (e.g., Mivart 1871). Only when the wing reached a sufficient size and strength could it be useful for enabling powered flight, meaning that natural selection could not favor variants within a population on the basis of flight ability during the early stages of wing evolution. So, how then could wings have evolved to serve their current function in flight? The answer is that early wings did not function in flight but served a different function (primary adaptation). Bird feathers, for example, probably originated for thermoregulation and rudimentary wings may have been useful in capturing prey or assisting with running uphill or one or more other functions (e.g., Dial 2003). In bats, early skin flaps probably would have been functional for gliding but not in powered flight (e.g., Bishop 2008). In insects, it has been hypothesized that early "wings" were used for skimming across the surface of water (Marden and Kramer 1994; Marden and Thomas 2003). Natural selection enhancing early forms of the structurewhich, initially, may not have been considered a "wing" at all had biologists examined it at the time-would have, at some point, brought it to a stage that could be useful in a new function (exaptation) resembling a rudimentary version of flight (for example, controlled descent from trees in birds and bats, or skimming with less contact with the water or powered jumps in insects). Further modification for this new semiflight function (secondary adaptation) would eventually render the structure suitable for yet another functional shift, namely to weak powered flight (exaptation again), with further modifications leading to new improvements specific to flight (secondary adaptation again).

Given that exaptations are defined largely by what they are not - namely, the products of natural selection strictly for their current function - there are several possible routes by which an organ, components of an organ, or genes can become exaptations (Gould and Vrba 1982; Arnold 1994; Gould 2002; McLennan 2008):

1. One organ (or gene) has an existing function but takes on or switches to a new function as a result of selective pressures experienced after the organism moves into a new environment or adopts a new ecological lifestyle. Arnold (1994) distinguishes between "addition exapta- 


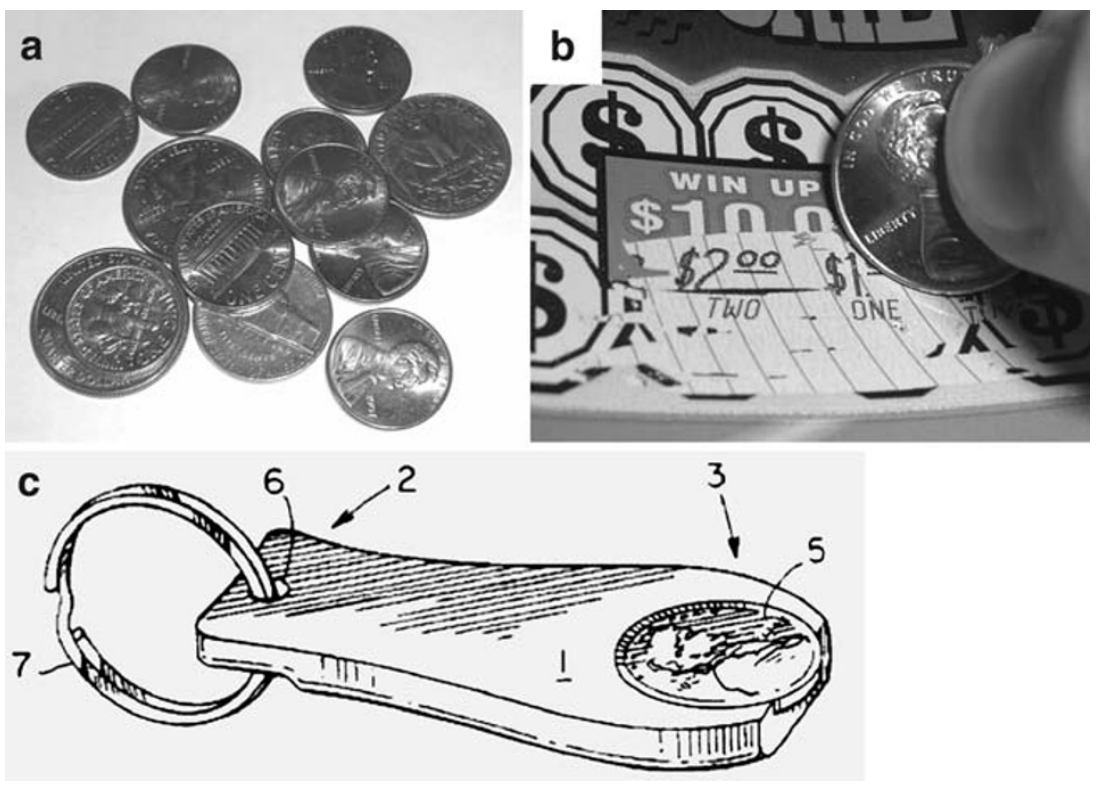

Fig. 2 A simple example of exaptation and secondary adaptation. A The original and still primary adaptive function of coins is as currency. B A coin co-opted into a new exaptive role as an instant lottery ticket scraper. Coins would always have been capable of scraping tickets, but this function did not become apparent until an environment arose in which instant lottery tickets were abundant. Though functional as scrapers, coins are somewhat difficult to hold and may not reliably be on hand when needed. C A secondary adaptation that enhances the novel function of a coin as a ticket scraper by incorporating it into a keychain that is easier to grip (US Patent \#6009590, "Lottery ticket scraper incorporating coin" by K.M. Stanford 2000). In this case, a second preexisting structure (key ring) was co-opted into a function as a carrier for a lottery ticket scraper tions" in which a second function is acquired in addition to the initial function and "transfer exaptations" in which the shift to a new function involves the loss of the previous function. Example: the middle ear bones of mammals are derived from former jaw bones (Shubin 2007).

2. One organ (or gene) has an existing function but at some stage modification of the feature for the initial function makes it amenable to modification in a new role and this allows the organism to move into a new environment or adopt a new ecological lifestyle. Example: early tetrapod limbs were modified from lobe-fins and probably functioned in pushing through aquatic vegetation; at some point, they became sufficiently modified to allow movement on to land (Shubin et al. 2006).

3. One organ (or gene) has two functions and is modified as it becomes increasingly specialized for one of them. Sometimes, the organ is specialized for one of the initial functions in one lineage and for the other initial function in a different lineage. Example: an early gas bladder that served functions in both respiration and buoyancy in an early fish became specialized as the buoyancy-regulating swim bladder in ray-finned fishes but evolved into an exclusively respiratory organ in lobe-finned fishes (and eventually lungs in tetrapods; Darwin 1859; McLennan 2008).

4. Two organs (or genes) perform the same function and then one becomes more specialized for the original function while the other takes on a different role. This is particularly significant when duplication generates multiple copies that subsequently diverge (see below). Example: some of the repeated limbs in lobsters are specialized for walking, some for swimming, and others for feeding.

5. A feature that had become vestigial ${ }^{2}$ in terms of its original function takes on a new function in its reduced state. Example: the vestigial hind limbs of boid snakes are now used in mating (Hall 2003).

6. A feature that formerly had no function and was present for non-adaptive reasons (a "spandrel"; Gould and Lewontin 1979; Gould 1997, 2002) takes on a function and may become specialized for that function. This, too, can occur at both the genetic level and the organ level. Arnold (1994) considers these "first-use exaptations" because the first function they fulfill is the exaptive one. Examples: the sutures in infant mammal skulls are useful in assisting live birth but were already present in nonmammalian ancestors where they were simply byproducts of skull development (Darwin 1859); some formerly parasitic transposable elements in the genome, which had no function at the organism level, have been co-

\footnotetext{
2 "Vestigial" does not necessarily mean non-functional, it means reduced in form and function in a particular species relative to others in which the organ still performs the original function. Thus, finding some function for a reduced organ, which is often different from the function of the fully formed organ in other species, does not affect its status as being vestigial.
} 
opted into a variety of other roles, such as in the vertebrate adaptive immune system (e.g., Zhou et al. 2004).

The important point regarding exaptations, then, is that the current function of a feature may not reflect the reasons for its origin. Rather, the feature may only have come to occupy its current role comparatively recently.

\section{Duplication (or Furcation)}

It has long been recognized that natural selection, though capable of producing directional change, can also be a highly conservative force. If a biological feature currently serves a function vital to survival, then it is very likely that any deviations from its current state will prove detrimental. That is to say, individuals with a different form of the feature will leave fewer offspring than those with the original form, such that there will not be change in the population from one generation to another with regard to this feature. The most widely recognized escape from this constraint is through duplication, a topic that has long been discussed in some detail with reference to genes (e.g., Ohno 1970; Taylor and Raes 2004). Ohno (1970), in particular, considered duplication and divergence of genes a critical requirement for major evolutionary diversification: "Natural selection merely modified while redundancy created," he wrote.

In general, four different outcomes are possible following a gene duplication event. One, the duplicate copy (or the original) may simply be lost or rendered nonfunctional by mutation (to become a "pseudogene"). Two, multiple copies may prove to be beneficial such that their repetition is maintained by selection thereafter ("isofunctionalization"; Oakley et al. 2006). As an interesting example, the number of functional copies of the salivary amylase gene, which is involved in breaking down starch, is higher in human populations where starchy foods are common in the diet (Novembre et al. 2007; Perry et al. 2007). Three, mutations in different parts of the two gene copies may mean that both copies must be retained in order to fulfill the original function, or one copy may come to serve the original function in one tissue or at one time during development while the second copy is active in different places or at different times, again such that both copies are needed to serve the role of the original gene ("subfunctionalization"). Four, as per Ohno's (1970) discussion, one copy may take on a new function while the other fulfills the previous function ("neofunctionalization").

Repeated structures are common at the organism level as well-body segments, teeth, and flower petals are among the many examples. In this case, duplicated structures may remain in repeated series (e.g., identical body segments of myriapods or annelids), one of the two repeats may retain the original function while the other takes on a new function (e.g., the reduced hind wings of true flies, called "halteres," which now function as a kind of gyroscope), or the repeats may become specialized for different functions that are either new or are functions that were formerly carried out by a single structure (e.g., specialized appendages in crustaceans). Darwin (1859, p.437-438), himself, recognized the importance of duplication at the organism level when he wrote:

We have formerly seen that parts many times repeated are eminently liable to vary in number and structure; consequently it is quite probable that natural selection, during a long-continued course of modification, should have seized on a certain number of the primordially similar elements, many times repeated and have adapted them to the most diverse purposes.

Although there clearly are similarities between the gene and organism levels in this regard, it is important to note that duplication of structures (e.g., organs or components thereof) may not necessarily be the result of the duplications of genes. Organ-level multiplication can also occur with regulatory mutations that cause the feature to appear in different places, at different times, or in repeated series. To clarify this issue, Oakley et al. (2007) recently coined the term "furcation" (meaning "formation of a fork or division into branches") to cover the multiplication of existing structures more generally. The important point for the present discussion is that duplications, whatever their cause and with or without divergence, can be an important mechanism for increasing complexity at both the genomic and organismal levels.

\section{Gene Sharing}

Under the process of "addition exaptation", a feature that is functional in one capacity assumes a second function without losing its original function (Arnold 1994). At the molecular level, it is becoming increasingly recognized that the same protein can carry out more than one function, though it can sometimes be difficult to determine which, if either, was the sole original function. In this sense, a descriptor other than "exaptation" or "co-option" is used in reference to the existence of multifunctional proteins: "gene sharing" (Piatigorsky 2007, 2008).

\section{As Piatigorsky (2007, pp 4-5) defines it,}

The term "gene sharing" means that one gene produces a polypeptide [protein] that has more than one molecular function: Two or more entirely different functions of a polypeptide share the identical gene.... The gene-sharing concept postulates that protein function is determined not only by primary amino acid sequence, which remains the same in the multiple functions that are performed by the protein, but also by the microenvironment within the cell and by the expression of its gene. Awareness of gene sharing cautions against assuming that a protein will be 
used in the same way wherever or whenever it is present, or that it has always done what it is doing at any given moment. The functions of genes and proteins are context dependent.

There are several ways that a single protein can serve very different functions, such as by being expressed in different tissues or at different times during development (i.e., due to changes in regulatory genes), by undergoing changes in the amino acid sequence that enable a second function but do not compromise the first, by combining with another copy of the same protein to form a "homodimer" with a different function, by combining with other proteins to form "heterodimers," or by being subject to different patterns of folding or other chemical modifications (True and Carroll 2002; Piatigorsky 2007).

The process of gene sharing can be important in the evolution of complex organs because it means that functions can be enhanced or acquired without any change in the proteincoding gene itself if there is a change in the context in which it occurs - say, the emergence of a new type of tissue in which it may be expressed. Conversely, an existing gene being expressed in a new place in the body may itself lead to the evolution of a new tissue. This greatly facilitates the specialization of an organ for a new function because it does not compromise previous functions for the gene, does not require gene duplication and divergence (though this remains an important process in its own right), and may involve little more than a quantitative change in the amount or localization of the gene's protein product.

\section{Bricolage (Tinkering) and Collage}

In light of the processes described above, it may seem an obvious point that the evolution of complex organs does not involve redesign from scratch at each stage; whether by direct adaptation or shifts in function, the process builds upon and modifies what is already present. This was recognized by early evolutionists including Darwin (see Jacob 1977, 1982; Laubichler 2007) but has often been overlooked when authors characterize natural selection as an optimization process. The clear exposition by Jacob $(1977,1982)$ was therefore an important reminder of this point, from which it is worth quoting at length (Jacob 1982, pp 33, 34):

The action of natural selection has often been compared to that of an engineer. This comparison, however, does not seem suitable. First, in contrast to what occurs during evolution, the engineer works according to a preconceived plan. Second, an engineer who prepares a new structure does not necessarily work from older ones. The electric bulb does not derive from the candle.... To produce something new, the engineer has at his disposal original blueprints drawn for that particular occasion, materials and machines specially prepared for that task. Finally, the objects thus produced de novo by the engineer, at least by the good engineer, reach the level of perfection made possible by the technology of the time.

In contrast to the engineer, evolution does not produce innovations from scratch. It works on what already exists, either transforming a system to give it a new function or combining several systems to produce a more complex one. Natural selection has no analogy with any aspect of human behavior. If one wanted to use a comparison, however, one would have to say that this process resembles not engineering but tinkering, bricolage we say in French. While the engineer's work relies on his having the raw materials and the tools that exactly fit his project, the tinkerer manages with odds and ends. Often without knowing what he is going to produce, he uses whatever he finds around him... none of the materials at the tinkerer's disposal has a precise and definite function. Each can be used in different ways. What the tinkerer ultimately produces is often related to no special project. It merely results from a series of contingent events, from all the opportunities he has had to enrich his stock with leftovers. In contrast with the engineer's tools, those of the tinkerer cannot be defined by a project. What can be said about any of these objects is just that "it could be of some use." For what? That depends on the circumstances.

Though they describe more a principle than a process, the terms "tinkering" and "bricolage" include, and are now most often used as substitutes for, "co-option of a gene or other feature into a new function" or simply "mutation and natural selection leading to an alteration of preexisting traits" (e.g., Bock and Goode 2007). As Jacob (2001) noted, one must be cautious to avoid a potentially confusing anthropomorphism in which an actual tinkerer or bricoleur is imagined who invents through trial and error.

What is perhaps missing, and for the purposes of this discussion is useful to emphasize, is a particular process mentioned by Jacob (1977, 1982) that differs from both direct adaptation and exaptation, in which existing components, be they functional for something else or nonfunctional initially, are brought together or rearranged to form a new, more complex combination with a novel function. Rather than "bricolage," the term "collage" may more effectively encapsulate this concept. ${ }^{3}$ Because a new function emerges

\footnotetext{
${ }^{3}$ The terms "patchwork" and "jury-rigging" also have been used in this regard, but the first may imply a pre-determined design that is achieved using available materials whereas the latter often refers to the make-shift repair of damaged structures. Unfortunately, many terms currently in use such as "adaptation", "exaptation", "bricolage", and most recently "collage" suffer from potential confusion because they refer to both a process and its products. Further terminological refinement clearly is required.
} 
through the combination of existing components, and especially once further modified by natural selection for this new function, a feature produced through "collage" becomes much more than the sum of its parts. As noted by Jacob (1977, 1982), the feature is not assembled with a predefined outcome in mind, rather its function depends on circumstances and on which components are available and happen to become linked. Two important points bear mentioning about the process of indirect evolution through "collage": (1) the linking of components is not an "all or nothing" process in which two or more already complex structures suddenly are joined-individual parts, which themselves may variously be simple or relatively complex and functional for something else or nonfunctional, can be added in series, with each new addition leading to a different function for the combined structure and (2) the newly combined structure may carry out its new function rather poorly at first, with subsequent direct adaptation leading to improvement along this novel axis, for example by enhancing the integration of the newly combined components (Fig. 3).

\section{Scaffolding}

Many organs, having been built up in overall complexity by direct adaptation, exaptation, and collage, and further specialized through secondary adaptation, exhibit a level of integration to the point that their components are interdependent on one another. In these cases, the removal of one or more components may render the organ nonfunctional-at least with regard to its current integrated function (after all, exaptation can also occur following a loss of parts). Shifts in function help to explain how such a system could be assembled through less complex intermediate steps, but another process known as "scaffolding" is sometimes involved in the evolution of such functionally indivisible organs. In this case, a component of the organ that is present

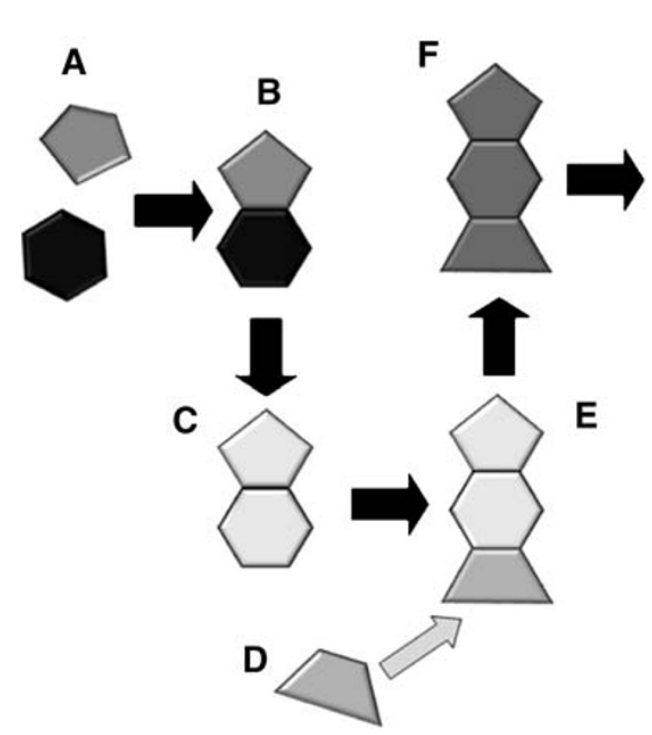

Fig. 3 A diagram showing the processes of exaptation (shifts in function), collage (assembling existing elements into new functional combinations), scaffolding (loss of a component that was formerly required for the assembly of a complex arrangements of parts), and direct adaptation by natural selection (including secondary adaptation) in the evolution of a complex feature. The complex organ $(J)$ includes many parts, all of which must be present for the organ to carry out its current function. Although it can now carry out this function only when all of its components are present, an organ such as this can evolve through intermediates, all of which have some function - though not necessarily the function of the final complex organ $(J)$. At an early stage, two simple structures, each already present and performing its own distinct function $(A)$, come together into a combined structure $(B)$ that is capable of carrying out a function that neither component could before. At first, the combined structure $(B)$ may perform the new function rather poorly, but if it nonetheless confers some advantage over alternatives lacking the structure, then the components may be modified by natural selection favoring improvements in this new function $(C)$. Later, a third

component $(D)$, which was also already present and serving its own function, is co-opted and becomes associated with the simple two-part organ to form a three-part organ $(E)$ capable of performing yet another new function (though, again, not the one currently filled by $J$ ). Once again, the various components may become modified due to selection favoring improvements to this new function $(F)$. Later, additional components $(G)$-which in this case are themselves built of combined, perhaps duplicated, components - become associated with the modified three-part organ $(F)$ to form a complex but still not irreducibly complex organ $(H)$ that takes on the function of the final complex organ, albeit not very effectively. This complex organ is, once again, modified for its new function and most of the components become more closely integrated (I). However, one component that has become structurally unnecessary is lost (e.g., because it is costly to produce and mutations that lead to lower investment in its production are advantageous), leaving behind an irreducibly complex organ $(J)$ whose ability to carry out its current function is contingent on the presence of all its component parts 
through some early stages has the effect of supporting the assembly of other components and, when lost in later stages, leaves behind a complex structure that by all appearances could not have been assembled one piece at a time (Fig. 3).

Draper (2002) has provided an abstract description that is readily applied to biological systems (including organs or biochemical pathways). In this case, a complex system with two required parts $(\mathrm{AB})$ that performs a function $(\mathrm{F})$ evolves through a complicated but essentially direct path involving both the addition and loss of parts:

Originally, Z performs $\mathrm{F}$, though perhaps not very well (this is possible because, from the fact that $\mathrm{AB}$ cannot perform $\mathrm{F}$ without $\mathrm{A}$ or $\mathrm{B}$, it does not follow that $\mathrm{Z}$ cannot perform $\mathrm{F}$ by itself). Then, $\mathrm{A}$ is added to $\mathrm{Z}$ because it improves the function, though it is not necessary. B is also added for this reason. One now has a reducibly complex system composed of three parts, $\mathrm{Z}$, $\mathrm{A}$, and B [i.e., the system could still function if the number of parts is reduced]. Then $\mathrm{Z}$ drops out, leaving only A and B [perhaps only after A and B have become modified to work in a more integrated fashion in their new joint arrangement]. And without $\mathrm{Z}$, both $\mathrm{A}$ and $\mathrm{B}$ are required for the system to function.

This can perhaps be illustrated even more simply with a straightfoward architectural analogy involving the construction of a stone arch (e.g., Cairns-Smith 1985; Dawkins 1986; Schneider 2000; Thornhill and Ussery 2000). As Dawkins (1986, p.149) put it:

An arch of stones...is a stable structure capable of standing for many years even if there is no cement to bind it. Building a complex structure by evolution is like trying to build a mortarless arch if you are allowed to touch only one stone at a time. Think about the task naïvely, and it can't be done. The arch will stand once the last stone is in place, but the intermediate stages are unstable. It's quite easy to build the arch, however, if you are allowed to subtract stones as well as add them. Start by building a solid heap of stones, then build the arch resting on top of this solid foundation. Then, when the arch is all in position, including the vital keystone at the top, carefully remove the supporting stones and, with a modicum of luck, the arch will remain standing.

A second issue is that a stone does not become a keystone until it is added to the rest of the assembled arch, and serving this role cannot be the reason it is maintained until that point. This is analogous to a component of a complex organ that can be incorporated only relatively late in the process, and therefore cannot be maintained for this function earlier in the process. One manner in which such components may remain present is if they serve a different function and are preserved more or less in their current form on that basis. In this regard, dual functionality may itself be a form of scaffolding that, in retrospect, will have played a role in facilitating the production of a complex feature.

Viewing a complex structure - be it an arch (or, for that matter, the Great Pyramids or Stonehenge), an organ, or a biochemical pathway - only as it appears in the present, with no consideration of the scaffolding that may have been involved in its construction, can lead to undue pessimism regarding the plausibility of its assembly by comparatively unremarkable processes.

Non-adaptation: Constraints, Trade-offs, and Historical Contingency

In the sixth and final edition of The Origin of Species, Darwin (1872, p 421) expressed the following frustration:

[As] it has been stated that I attribute the modification of species exclusively to natural selection, I may be permitted to remark that in the first edition of this work, and subsequently, I placed in a most conspicuous position - namely, at the close of the Introduction - the following words: "I am convinced that natural selection has been the main but not the exclusive means of modification." This has been of no avail. Great is the power of steady misrepresentation.

Natural selection is not the only mechanism involved in evolution. It is not even the only process that may account for the origin of biologically complex systems (e.g., Lynch 2007a, b). It may be the creative process responsible for generating adaptive complexity, but this does not mean that its influence is without limits; constraints of various sorts (e.g., genetic, developmental, physical, energetic, historical) also contribute to the observed form of complex features. For example, although one may conceive of a change that would improve the function of an organ, it may be that the necessary mutations (which occur by accident and not in response to need) simply never arose. It could be that changes in an organ would be too disruptive to existing developmental programs to be viable, could not physically be accommodated within the morphology of the organism carrying the organ, or would compromise the function of other organs through trade-offs. Or, it could be that there simply was no selective pressure in the environment that would favor increased complexity in a particular organ. Moreover, some characteristics of complex systems are not adaptive at all, but represent the inevitable byproduct of other evolutionary changes (Gould and Lewontin 1979; Gould 2002) or mechanisms (Lynch 2007a, b). Therefore, an important point to bear in mind about complex organs is this: not everything about them should be viewed in the light of adaptation. 


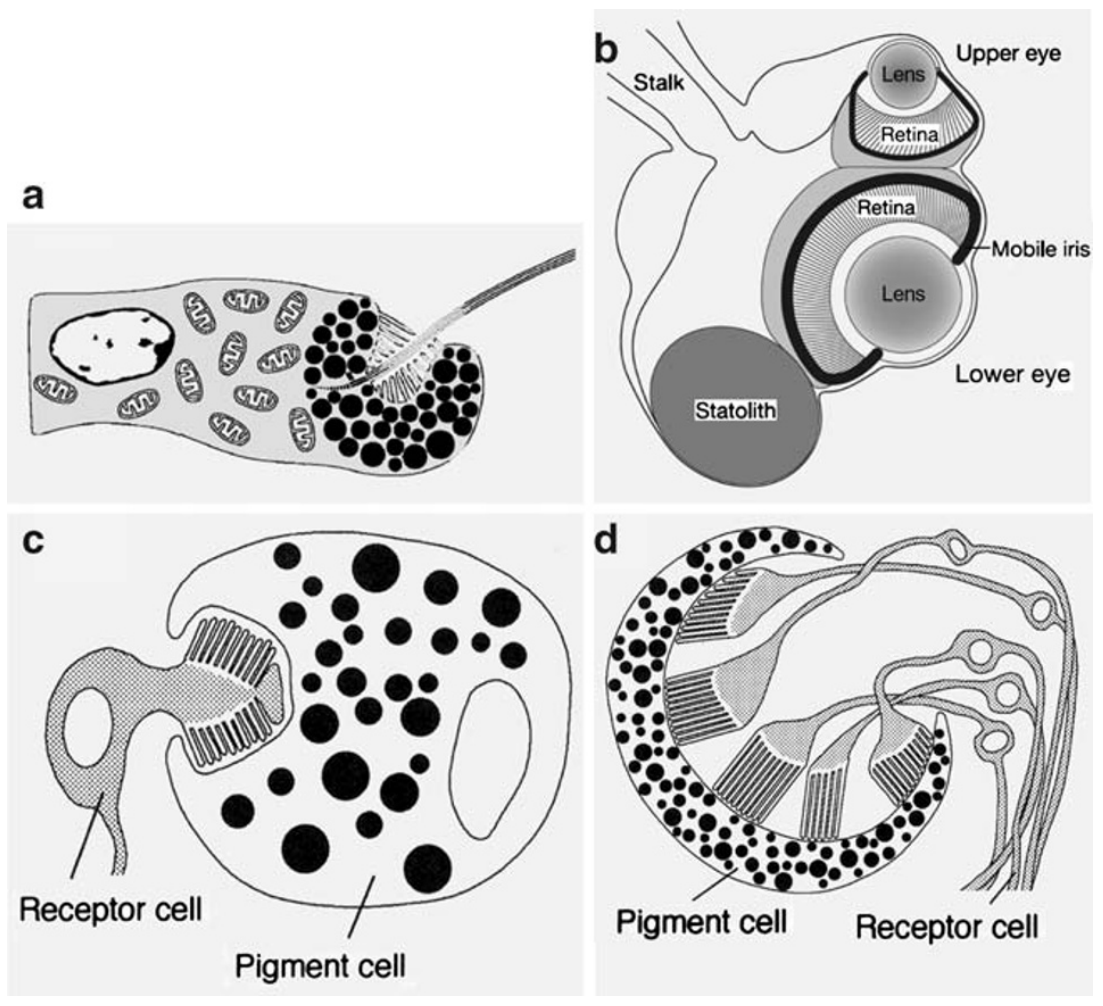

Fig. 4 Very simple, but nonetheless functional, light-sensing systems. A A single light-sensitive cell (ocellus) as found in the larva of the box jellyfish Tripedalia cystophora. In this case, the light-sensitive cell is not connected to a nervous system of any kind but instead includes a cilium that can be stimulated to move the larva in response to light. The pigments (dark spots) within the cell are arranged in a simple cup, meaning that some measure of the directionality of light is provided to the cell. From Nordström et al. (2003), reprinted by permission of The Royal Society. B In stark contrast, the adult of the same box jellyfish species, T. cystophora, has complex upper and lower eyes with retinas, lenses, and irises at the end of a sensory club called a rhopalium. From Nilsson et al. (2005), reproduced by permission of Nature Publishing Group. C A simple eye spot found

\section{Case Study: The Evolution of Eyes}

The eye has long held a special place in discussions regarding the origin of complex organs. Paley (1802) famously compared the intricacies of an eye to those of a finely crafted watch and concluded that both were the work of an intelligent designer. ${ }^{4}$ Darwin (1859) offered a different explanation for the origin of biological complexity and again used the eye as a prominent example. Thus, in a passage that is often (partially) quoted, Darwin $(1859$, pp 186, 187) remarked:

To suppose that the eye, with all its inimitable contrivances for adjusting the focus to different distances,

\footnotetext{
${ }^{4}$ It bears noting that Darwin read Natural Theology (Paley 1802) as a theology student at the University of Cambridge between 1827 and 1831 , and noted in his autobiography that "I did not at that time trouble myself about Paley's premises; and taking these on trust, I was charmed and convinced by the long line of argumentation" (Darwin 1958, p.59).
}

in the larva of the trematode flatworm Multicotyle purvisi, which consists of one pigment cell and one photoreceptor cell. This organ itself provides no information about the direction of a light source, but this can be achieved by comparing the input from two of these organs. Redrawn by Land and Nilsson (2002) based on Rohde and Watson (1991), reproduced by permission of Oxford University Press. D A slightly more complex visual organ involving a single pigment cell but multiple receptor cells found in the turbellarian flatworm Bdellocephala brunnea. In this species, the pigment cell is cup-shaped, such that information about the direction of light can be obtained by comparing input from the different receptors. Redrawn by Land and Nilsson (2002) based on Kuchiiwa et al. (1991), reproduced by permission of Oxford University Press. Note that these images are not drawn to the same scale

for admitting different amounts of light, and for the correction of spherical and chromatic aberration, could have been formed by natural selection, seems, I freely confess, absurd in the highest possible degree. Yet reason tells me, that if numerous gradations from a perfect and complex eye to one very imperfect and simple, each grade being useful to its possessor, can be shown to exist; if further, the eye does vary ever so slightly, and the variations be inherited, which is certainly the case; and if any variation or modification in the organ be ever useful to an animal under changing conditions of life, then the difficulty of believing that a perfect and complex eye could be formed by natural selection, though insuperable by our imagination, can hardly be considered real.

A considerable amount of research has illuminated many details of eye evolution in different groups of animals since Darwin penned these words. The comparatively recent rise of 
disciplines including molecular biology, phylogenetics, and evolutionary developmental biology ("evo-devo"), in particular, has generated a great many insights regarding this subject. So much, in fact, that any more than a cursory review of the available information must be considered well beyond the scope of this article (however, references to papers containing this information are provided whenever possible). Instead, the eye is used as a case study to illustrate the various general principles of complex organ evolution outlined above, and in particular to demonstrate that the multifaceted nature of the topic requires that it be examined from a variety of perspectives.

\section{Eyes: Definition and Diversity}

According to some authors, an eye is defined at minimum as a photoreceptor shielded on one side by nearby pigment which allows the detection of the direction of a source of light. The simplest eyes, then, may consist of just one photoreceptor and one pigment cell or even a single cell that includes both photoand shading pigments as found in some flatworms and algae (e.g., Arendt and Wittbrodt 2001; Oakley 2003). Some examples of relatively simple "eyes" are shown in Fig. 4. Others argue for a more restrictive definition under which an eye is an organ that can produce an image, however crude, and not simply detect light (e.g., Land and Nilsson 2002; Piatigorsky 2008; Serb and Eernisse 2008). Even under this stricter definition, there are at least eight different types of eyes, ${ }^{5}$ prominent examples of which variously employ cups, pinholes, camera-type lenses, arrays of lenses, concave mirrors, or telescope-like arrangements for image formation (Land and Fernald 1992; Land and Nilsson 2002; Serb and Eernisse 2008). These are illustrated in Figs. 5 and 6. To the extent that the eyes of each species are at least slightly different from each other, and given that many species have more than one type of eyes, there are probably millions of different kinds of eyes peering at the world around them at this very moment.

There is no doubt that access to visual information has been important in a great many groups of organisms. Eyes can be found in about one third of the world's animal phyla while another one third has light-sensing organs but not eyes.

\footnotetext{
${ }^{5}$ For more detailed discussions of the form, function, and evolution of diverse animal eyes, see Land (1988), Nilsson (1989), Land and Fernald (1992), Arendt and Wittbrodt (2001), and Land and Nilsson (2002), or consult recent reviews on the eyes of specific groups including annelids (Purschke et al. 2006), crustaceans (Gaten 1998; Elofsson 2006; Reimann and Richter 2007; Marshall et al. 2007; Cronin and Porter 2008), tardigrades (Greven 2007), insects (Land 1997; Buschbeck and Friedrich 2008), velvet worms (Mayer 2006), millipedes (Müller et al. 2007), jellyfishes (Nilsson et al. 2005; Kozmik et al. 2008a, b), mollusks (Serb and Eernisse 2008), trilobites (Clarkson et al. 2006), horseshoe crabs (Battelle 2006), and vertebrates (Lamb et al. 2007, 2008).
}

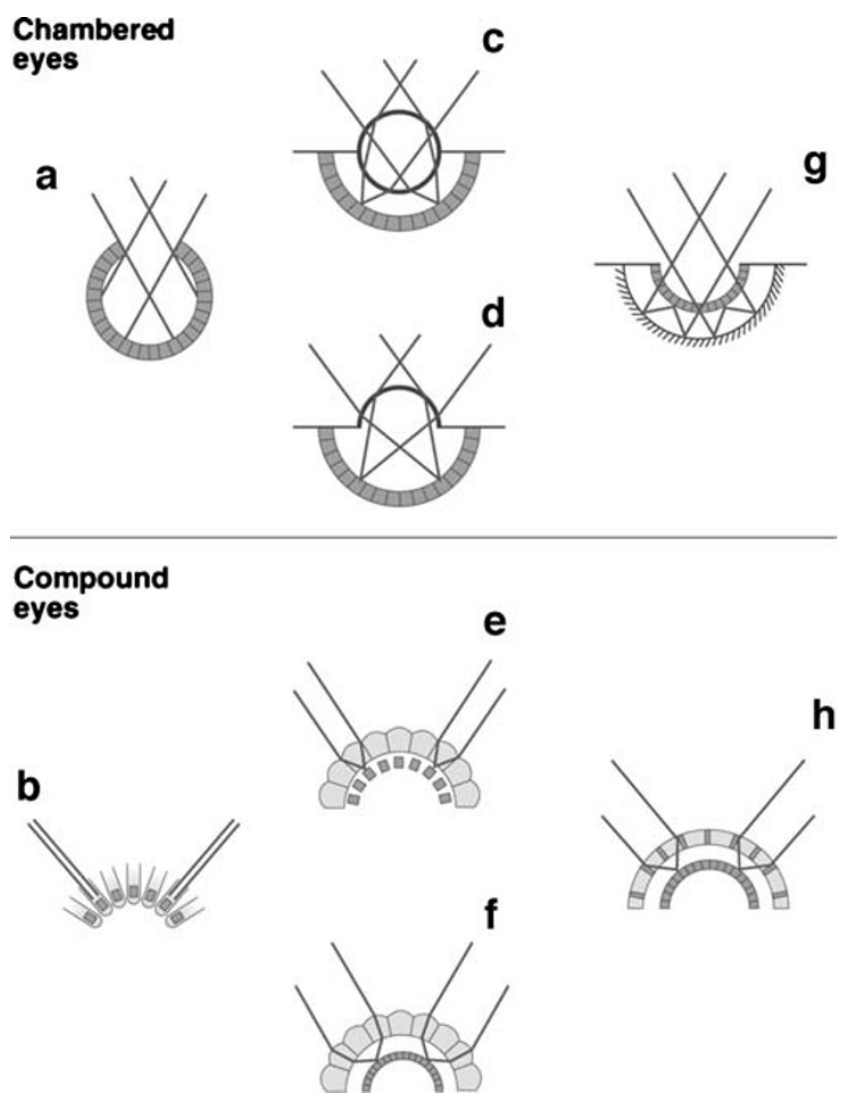

Fig. 5 Eight major types of complex eyes found in living animals, divided into two major categories: chambered eyes (top) and compound eyes (bottom). $(A)$ and $(B)$ form images using shadows, $(C)$ to $(F)$ use refraction, and $(G)$ and $(H)$ use reflection. The paths of light rays entering the eyes are indicated by dark lines. The photoreceptive structures are shown in shaded gray. (A) A simple pit eye, as found in Nautilus as well as many flatworms and annelids. (B) A basic compound eye in which each receptor is shielded from its neighbor by a simple pigment tube, as found in sea fans and a few bivalve mollusks. (C) A complex camera-type eye in which the lens does most of the focusing, as found in fishes and cephalopod mollusks. $(D)$ A complex camera-type eye in which the cornea does most of the focusing, as found in terrestrial vertebrates and spiders. $(E)$ An apposition compound eye, found in diurnal insects and many crustaceans. $(F)$ A refracting superposition compound eye, as found in invertebrates in dim environments such as krill and moths. $(G)$ A single-chambered eye in which an image is formed using a concave mirror, as found in some scallops. $(H)$ A reflecting superposition eye, similar to $(F)$ but with lenses replaced by mirrors, as found in lobsters and shrimps. Modified from Land and Nilsson (2002) and Fernald (2006), reproduced by permission of Oxford University Press and the American Association for the Advancement of Science

Roughly one third of the world's animal phyla have no light sensitive organs, but these tend to be groups exhibiting low diversity; by contrast, the phyla with eyes include more than 95\% of all animal species (Land and Nilsson 2002; Fernald 2004a; but see de Quieroz 1999). The extraordinary benefits provided by the ability to see are also shown by the fact that eyes appeared very early in animal evolution. In fact, most of the major types of eyes are recognizable in fossils from the Cambrian some 530 Mya (Land and Nilsson 2002; Nilsson 


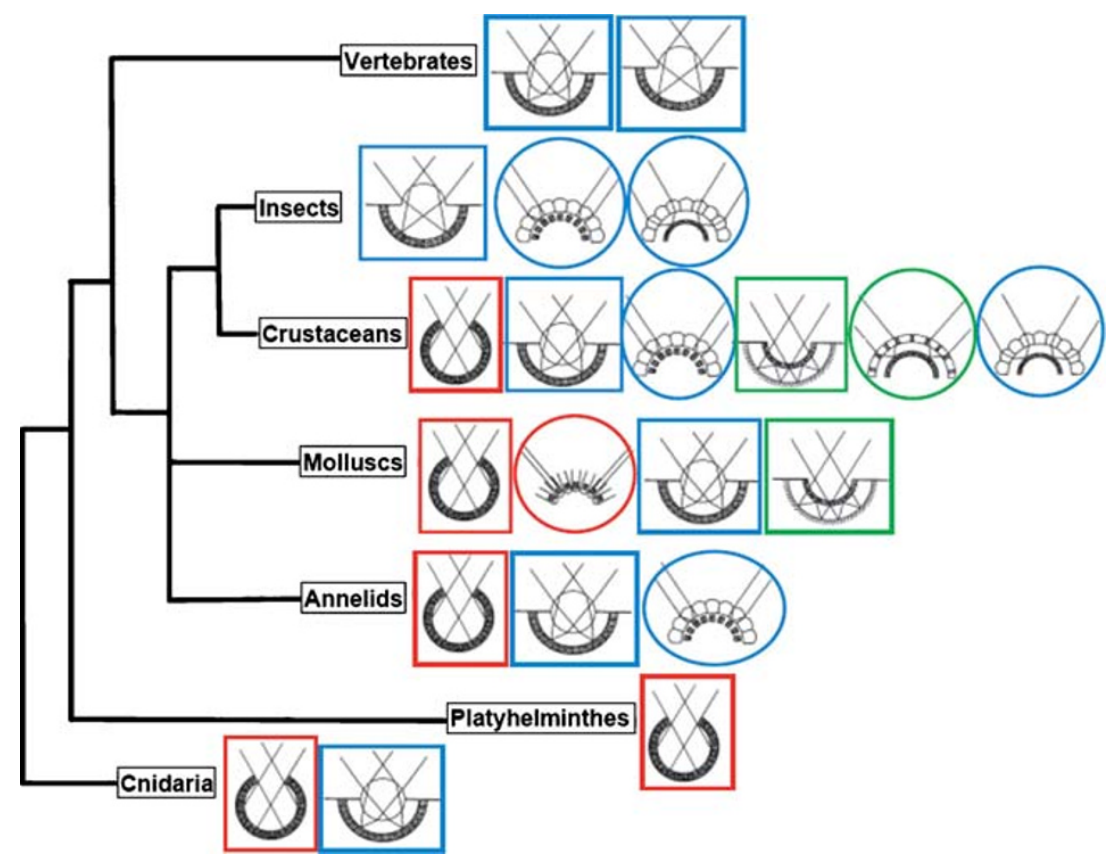

Fig. 6 The distribution of eye types among major taxa of animals. Single-chambered eyes are outlined with rectangles and compound eyes are outlined with ovals. See Fig. 5 for more information about the

2004). Interestingly, the phylum Chordata (of which humans are members) may have been among the last groups to evolve discernable eyes, as these were not present in the known Cambrian chordates (e.g., Pikaia); chordate eyes first appear in the fossil record of conodonts from 30 million years later (Land and Nilsson 2002). On the other hand, the extensive physical and molecular similarities between the eyes of lampreys and other vertebrates indicate that complex camera-type eyes were already present in their last common ancestor 500 Mya (Lamb et al. 2007).

There are several ways of categorizing complex imageforming eyes, such as by the type of photoreceptor cells, the arrangement of photoreceptors relative to pigment cells (i.e., inverted or everted), or by the mechanism of image formation (via shadows, refraction, or reflection; e.g., Land and Nilsson 2002; Fernald 2004a, b). Perhaps the best-known distinction is between chambered (or simple) and compound eyes (Nilsson 1989; Land and Nilsson 2002; Fernald 2006). Although based on a very narrow sampling of animal diversity, it is clear that most references to the evolution of "the" eye relate to the chambered, camera-type lens eyes found in humans and other vertebrates, as well as in cephalopod mollusks, some annelid worms, and various arthropods including spiders. Certainly, these are the most effective at image formation and are the most familiar, and they will form the basis of most of the remaining discussion. However, the evolution of compound eyes is no less interesting than that of chambered eyes - and, given the extraordinary diversity of groups exhibiting them different types. From Treisman (2004), reproduced by permission of The Company of Biologists and Oxford University Press

(most notably arthropods), this is an important question in biology (Land 1997; Nilsson and Kelber 2007; Buschbeck and Friedrich 2008; Cronin and Porter 2008).

\section{Direct Adaptive Evolution: From Eyespot to Eyeball?}

The simplest hypothesis for how a complex feature arose is one involving direct adaptive evolution, with incremental improvements in function favored at each stage by natural selection. Not surprisingly, this has been the starting point for many discussions of eye evolution, which is often depicted as a linear series of small changes, each of which adds very slightly to the organism's ability to process visual information (e.g., Salvini-Plawen and Mayr 1977; Miller 1994; Nilsson and Pelger 1994; Osorio 1994; Dawkins 1996; Bahar 2002; Kutschera and Niklas 2004).

The major question under these linear scenarios is whether indeed each step along the path not only is functional but in fact increases some aspect of visual ability. In order to test this, and moreover to investigate how much time such a process might require, Nilsson and Pelger (1994) created a theoretical model that began with nothing more than "a flat patch of light-sensitive cells sandwiched between a transparent protective layer and a layer of dark pigment". In the model, they used incremental changes of $1 \%$ in one parameter at a time (length, width, or protein density) that improved visual acuity as calculated based on established optical principles. Their model proceeded through a series of changes including 


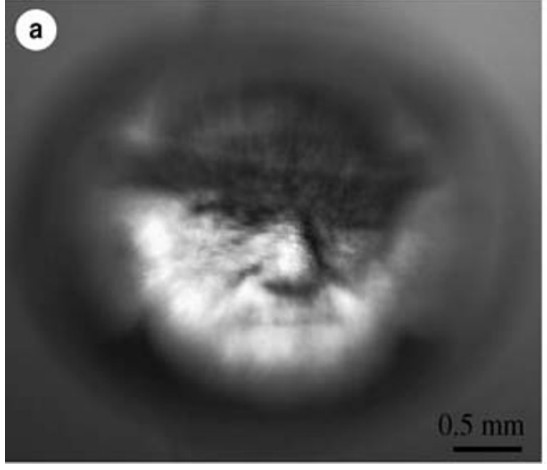

Fig. 7 The impacts of refinements in lens organization. (a) Image formed by a spherical glass bead with a single refractive index, showing the blurring resulting from spherical aberration. (b) The same image through the lens from a fish eye, which has a graded refractive index, resulting from a higher crystallin protein concentration in the centre than at the edges. Although the first "lens" may have functioned relatively

an inward folding of the flat patch to form a pit and then a cup, and when resolution could no longer be improved along this trajectory, a very simple lens was added (as they note "even the weakest lens is better than no lens at all") which then changed incrementally to become spherical and then to develop a gradient of refractive indices (Fig. 7), with the

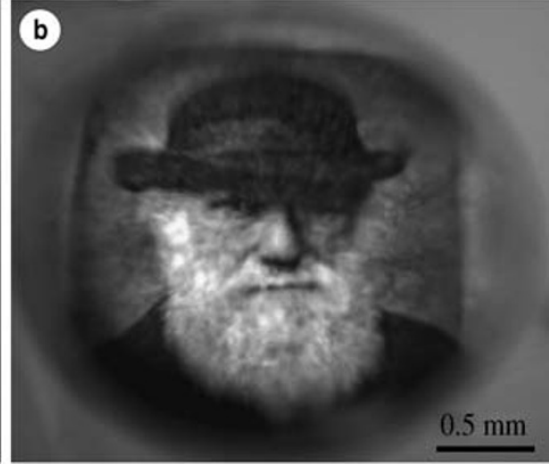

poorly, it is only a matter of incremental adaptive changes to improve its functioning to the level seen in modern camera-type lens eyes. For images of eye lenses focusing light from a laser, see Piatigorsky (2007, 2008). From Sweeney et al. (2007), reproduced by permission of The Royal Society and A.M. Sweeney

visual organ finally becoming similar in basic form to the eye of an aquatic animal like a fish or octopus (Fig. 8).

Overall, Nilsson and Pelger (1994) found that small, incremental changes that improve vision by a quantifiable degree could connect both ends of the continuum, from a simple patch of cells to a complex camera-type eye. More-

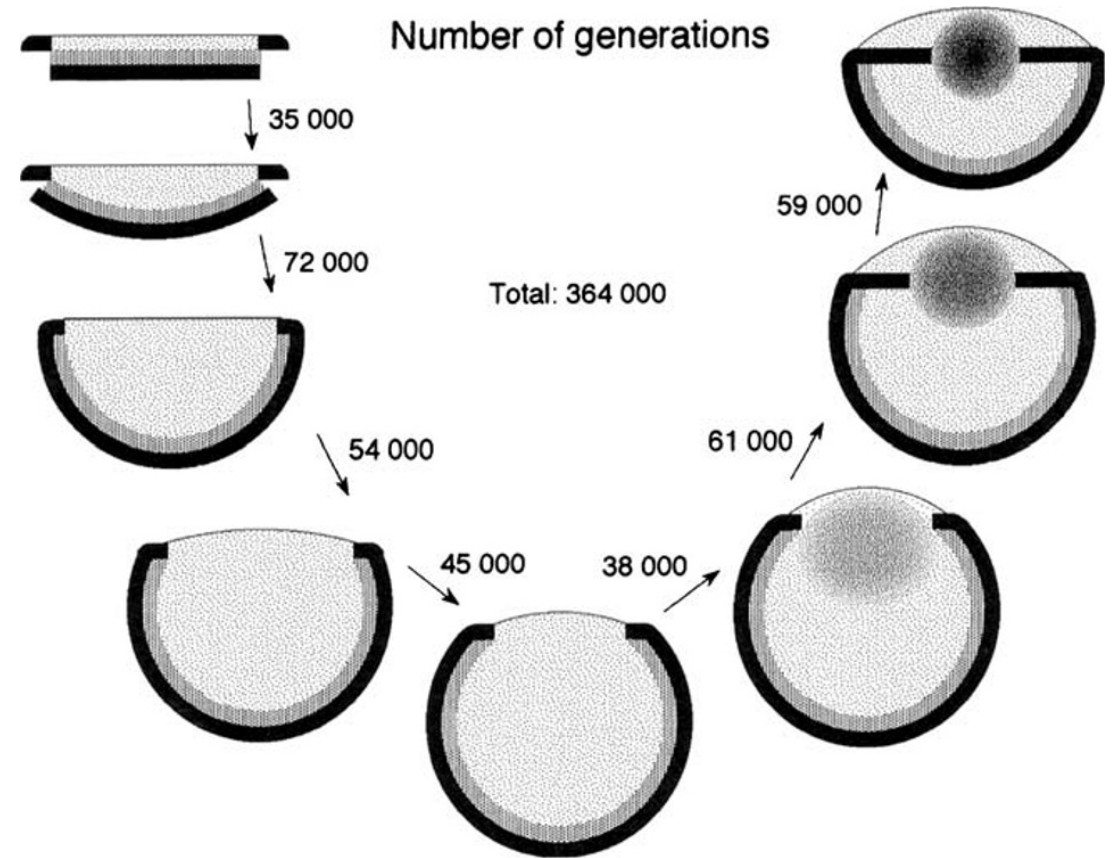

Fig. 8 The results of a theoretical model (not, as it is sometimes described, a "simulation") developed by Nilsson and Pelger (1994) to test the time required for a complex camera-type eye to evolve through a series of gradual steps from a simple patch of light-sensitive tissue consisting of an outer protective layer, a layer of receptor cells, and a bottom layer of pigment cells. The number of generations passing between each step is indicated, based on a change of only $0.005 \%$ in some parameter (length, width, or protein density) per generation with changes resulting in an improved calculated image formation retained each time. Although this model assumes a strictly gradualistic, linear model that is not necessarily the route that camera-type eye evolution actually took (Fig. 10; Table 1), it does show two important things: (1) that even very minor changes can improve image formation gradually and (2) that the time taken for this process to occur, less than 400,000 generations even under rather conservative assumptions, is remarkably fast in an evolutionary sense. From Land and Nilsson (2002) based on Nilsson and Pelger (1994), reproduced by permission of Oxford University Press and The Royal Society 
over, only 1,829 steps of $1 \%$ improvements were needed to complete this transition. Even assuming a change of only $0.005 \%$ per generation, the model suggests that the entire sequence could be completed in about 360,000 generations (Fig. 8). Given that many fishes and aquatic invertebrates have at least one generation per year, this would mean that the entire sequence in the model could be completed, to invoke an appropriate cliché, in an evolutionary blink of an eye and well within the tens of millions of years available during the Cambrian.

However, while the intermediate stages used by Nilsson and Pelger (1994) are functional in an abstract model, the most important question is whether organisms possessing them could actually survive in nature. It is in this regard that the approach of comparing living species becomes useful even though they are not ancestors and descendants of one another. In this way, it can be shown that each of the hypothetical intermediates depicted in Fig. 8 does still exist and clearly is functional for the organism in which it occurs. According to Land and Nilsson (2002, p.4), "nearly every imaginable intermediate exists between the acute vision of an eagle and the simple light sensitivity of an earthworm."
In fact, it has been recognized for over a century that such a diversity of eye types still exists (Darwin 1859; Conn 1900), as seen in Fig. 9.

It is important not to take linear models and comparisons of living species too far. Although they demonstrate how direct adaptive evolution could play a major role in the evolution of visual organs, their emphasis on linear transformation tends to obscure the complexity of the actual process. In the simplest terms, it is clear that a single, linear path of eye evolution is too simplistic even for comparisons among mollusks, which appear to have followed several distinct routes leading to divergent eye types (Fig. 10). In vertebrates there is ample evidence for the gradual evolution of eyes, but this does not follow the linear model given in Fig. 8. Indeed, the current hypothesis of vertebrate eye evolution involves at least one functional shift even at the organ level, from an early photoreceptive organ performing nonvisual circadian (day-night cycle) functions to a primitive eye capable of sight (Lamb et al. 2007, 2008; Table 1). As will be shown in the following sections, the influence of indirect evolutionary processes is even more pronounced at the level of the components of
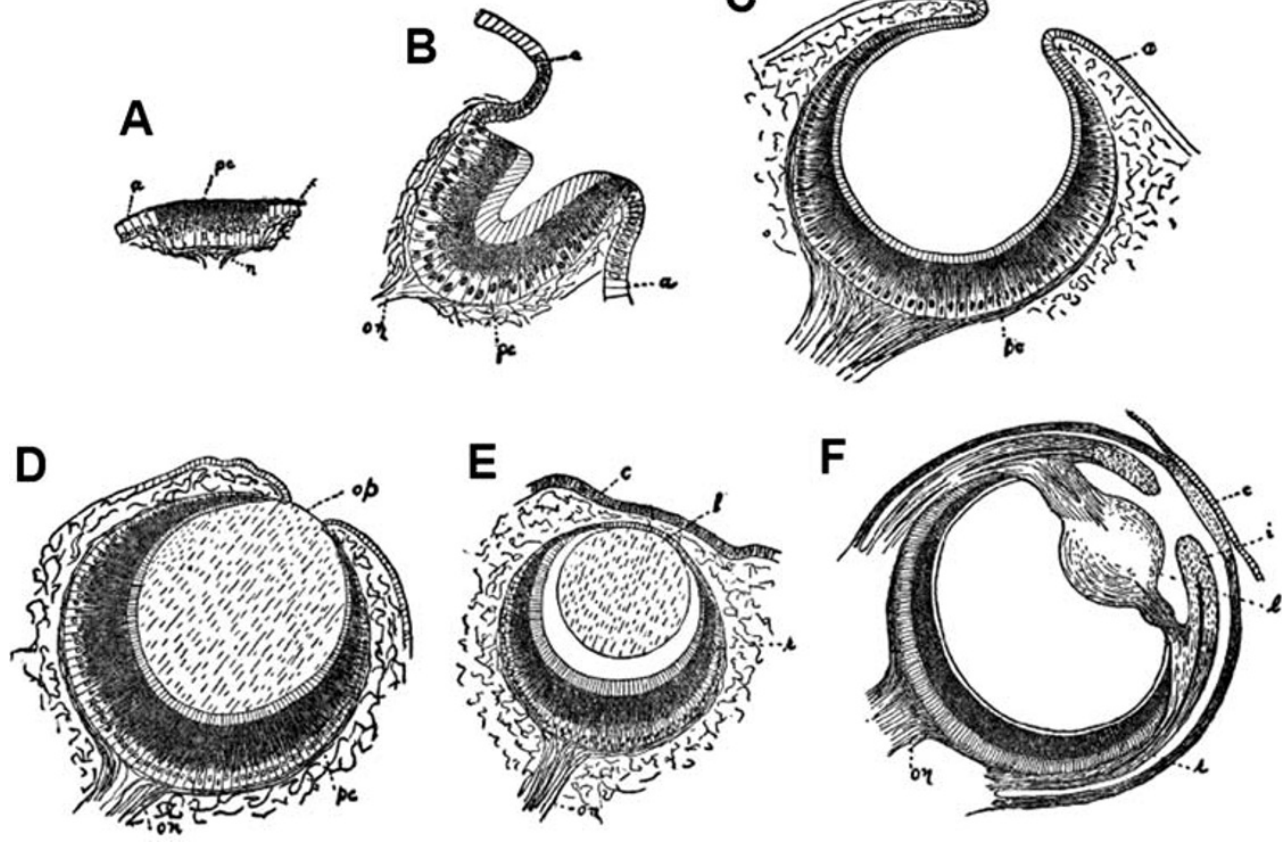

Fig. 9 Varying levels of complexity in the visual organs of living species as illustrated by H. W. Conn in 1900: A a simple, flat patch of pigmented cells connected to nerve fibers (see also Fig. 4C); B a slightly more complex pigment cup as found in the limpet Patella, which does not form an image but provides information about the direction of incoming light; $\mathbf{C}$ a pinhole camera-type eye filled with water as found in Nautilus; D a camera-type eye with a large lens filling the cavity; $\mathbf{E}$ a camera-type eye with a basic lens and cornea as found in the marine snail Murex; $\mathbf{F}$ a complex camera-type eye with a cornea, lens, iris, and retina as in a cuttlefish. This shows visual organs as they occur in contemporary species - none is ancestral to another, and this does not necessarily reflect a historical series of steps in the evolution of complex eyes (see Fig. 10). It does, however, indicate that eyes of varying complexity, such as would have been found in intermediate steps during complex eye evolution, could have beenand still are-functional for organisms living in different conditions. Note that these images are not drawn to the same scale. Modified from Conn (1900). For another classic example of this kind of diagram, see Salvini-Plawen and Mayr (1977) 

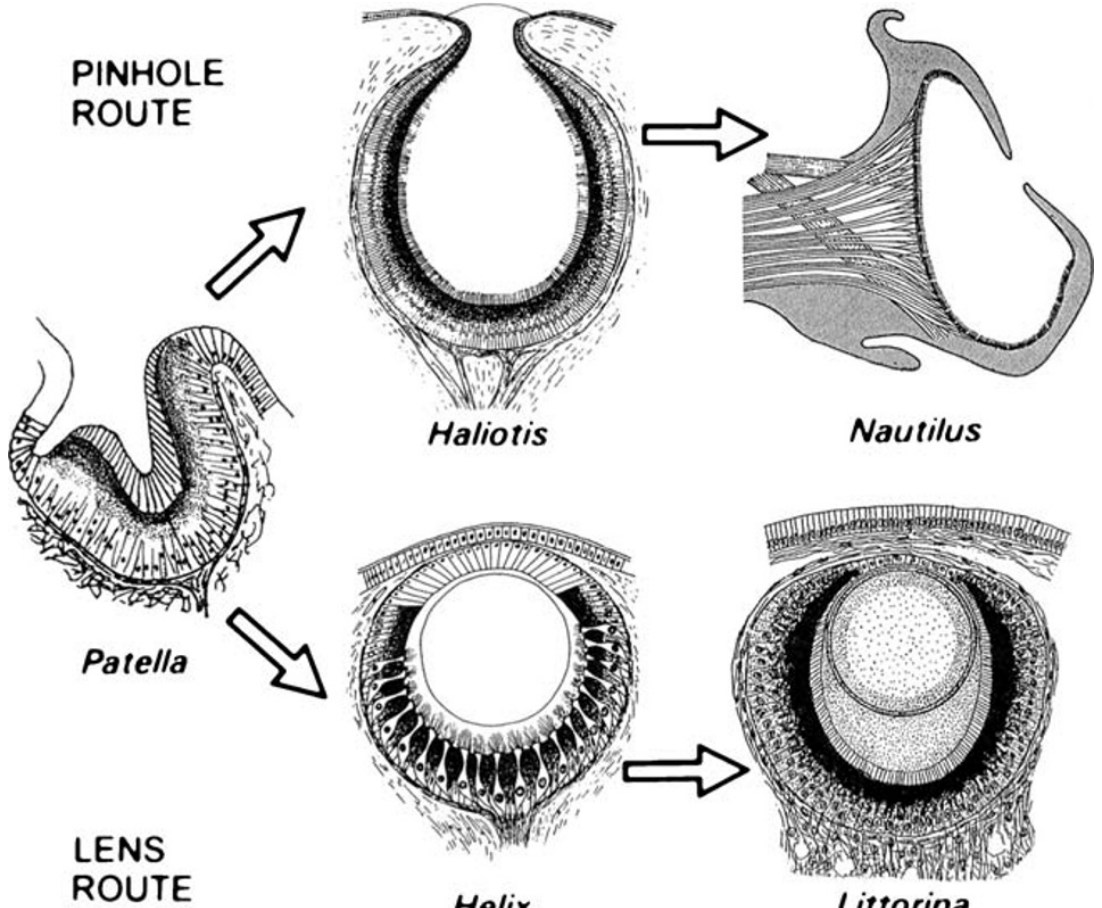

Haliotis

Nautilus

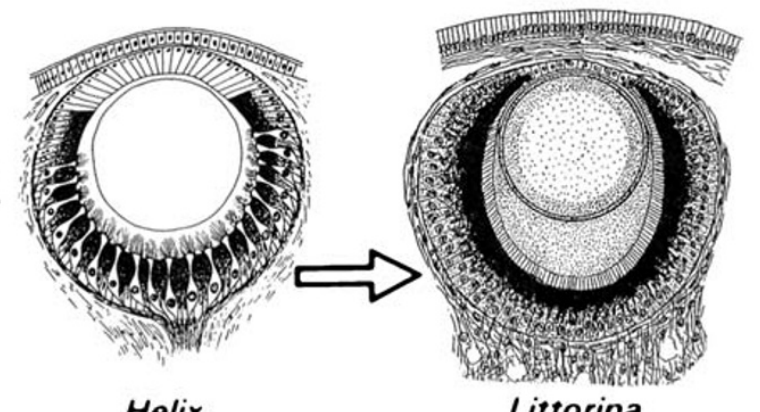

Helix

Littorina

Fig. 10 Two of the several paths of eye evolution followed in mollusks. Contrary to some representations of the eyes in Fig. 9, there is no simple linear series from eye patch to complex camera type eye. Rather, eyes may evolve in a variety of ways, becoming specialized as pinhole-type, lens-type, or other types of eyes from an early beginning. These are examples of eyes from modern species, and not actual ancestor-

camera-type eyes specifically involved in image formation, either in receiving light (photopigments and photoreceptors) or focusing it (lenses and corneas; Table 2).

Photopigments and Photoreceptors ${ }^{6}$

Vision is not the only function for molecules capable of reacting with light, and it should be no surprise that photosensitive molecules can be found not only in eyes but in animal tissues unrelated to vision as well as in plants, bacteria, and other types of organisms that do not see. The photopigments involved in vision, in particular, are made up of two components: (1) a light-sensitive molecule (chromophore) which changes physical conformation when it interacts with light; in all eyes studied to date this consists of a photosensitive molecule known as retinal that is derived

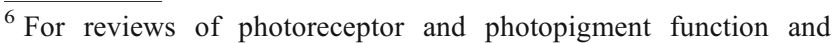
evolution, see Salvini-Plawen and Mayr (1977), Spudich et al. (2000), Ebrey and Koutalos (2001), Hisatomi and Tokunaga (2002), Arendt (2003), Gehring (2004, 2005), Terakita (2005), Plachetzki et al. (2005, 2007), Bowmaker and Hunt (2006), Purschke et al. (2006), Santillo et al. (2006), Lamb et al. (2007), Kawamura and Tachibanaki (2008), and Oakley and Pankey (2008).
}

descendant transitions. Note that these images are not drawn to the same scale (Nautilus eyes are about $10 \mathrm{~mm}$ across whereas the others are about $1 \mathrm{~mm}$ ). From Land and Nilsson (2002), based on drawings by Hesse (1908; Patella, Haliotis, and Helix), Young (1964; Nautilus), and Newell (1965; Littorina), reproduced by permission of Oxford University Press and Blackwell

from vitamin A, (2) a membrane-bound opsin protein that is involved in the chemical cascade that transduces the incoming light to an electrical signal. Opsins are members of a broad category known as $\mathrm{G}$ protein-coupled receptor proteins that also serve a range of nonvisual functions including chemoreception (Nilsson 2004). Both component molecules predate the origin of vision, and their merger and subsequent specialization in visual systems represents an important example of evolution through collage, exaptation, and secondary adaptation.

More than 1,000 distinct opsin molecules have been identified since the first example (bovine rhodopsin) was sequenced in 1982 (Terakita 2005). Those that occur in animals are divided into seven subfamilies, all of which appear to have originated before the split between the protostomes (most invertebrates) and deuterostomes (chordates and relatives including echinoderms) (Terakita 2005; Larusso et al. 2008). The extraordinary diversity of opsin molecules is likely a product of extensive gene duplication and subsequent divergence (Arendt 2003; Plachetzki and Oakley 2007; Oakley and Pankey 2008). Importantly, the duplication of opsin genes and their divergence in becoming reactive to different wavelengths of light forms the basis of color vision (e.g., Dulai et al. 1999; Spady et al. 2006; Briscoe 2008; Gerl and Morris 2008). 
Table 1 Summary of the steps in the evolution of vertebrate eyes as proposed by Lamb et al. (2007)

\begin{tabular}{|c|c|c|c|}
\hline Time (Mya) & Characteristics/changes & Comments & Functional? \\
\hline$>580$ & $\begin{array}{l}\text { Bilaterally symmetrical animals evolve } \\
\text { Various G-protein-coupled signaling } \\
\text { cascades evolve and initially may function } \\
\text { only in sensory systems other than vision } \\
\text { (e.g., chemoreception) } \\
\text { Early opsins (G-protein-coupled receptor } \\
\text { proteins) evolve } \\
\text { Early rhabdomeric and ciliary photoreceptors } \\
\text { evolve }\end{array}$ & $\begin{array}{l}\text { Some components may have functions other } \\
\text { than in light detection, and may work } \\
\text { together in a simple light response system } \\
\text { in the absence of any visual organ }\end{array}$ & $\begin{array}{l}\text { Yes. Similar to the light sensing capability } \\
\text { of soil-dwelling nematodes that lack any } \\
\text { type of eyes }{ }^{\mathrm{a}}\end{array}$ \\
\hline $580-550$ & $\begin{array}{l}\text { Ciliary photoreceptors and opsins continue } \\
\text { to be modified }\end{array}$ & Organ serves as a simple light detector & $\begin{array}{l}\text { Yes. Similar level of complexity as found } \\
\text { in some modern non-vertebrate chordates }\end{array}$ \\
\hline $550-530$ & $\begin{array}{l}\text { Ciliary photoreceptor gains more complex } \\
\text { signal transmission capabilities } \\
\text { Eye-field region of brain bulges to form } \\
\text { lateral "eye vesicles" outside of the newly } \\
\text { evolved skull } \\
\text { Lateral vesicles invaginate, bringing the } \\
\text { proto-retina next to the proto-retinal } \\
\text { pigment cell layer } \\
\text { A transluscent layer of cells (a primordial } \\
\text { lens placode) evolves and prevents } \\
\text { pigmentation of skin over the light- } \\
\text { sensing organ }\end{array}$ & $\begin{array}{l}\text { No image-forming capabilities, but the organ } \\
\text { can detect shadows or serve a circadian } \\
\text { function }\end{array}$ & $\begin{array}{l}\text { Yes. Similar level of complexity as found } \\
\text { in modern hagfishes and larval lampreys }\end{array}$ \\
\hline $530-500$ & $\begin{array}{l}\text { Photoreceptors develop cone-like features } \\
\text { Duplication of genome creates multiple } \\
\text { copies of phototransduction genes } \\
\text { Cell types of photoreceptors diverge in form } \\
\text { and have distinct opsins } \\
\text { Retinal information processing capability } \\
\text { increases as neural changes take place } \\
\text { Lens placode invaginates and forms into a } \\
\text { simple lens } \\
\text { Iris develops and basic pupil constriction is } \\
\text { possible } \\
\text { Extraocular muscles evolve }\end{array}$ & $\begin{array}{l}\text { Eye has image-forming capabilities and can } \\
\text { operate over a relatively broad spectrum } \\
\text { of light and range of light intensities }\end{array}$ & $\begin{array}{l}\text { Yes. Similar to the eyes of modern adult } \\
\text { lampreys }\end{array}$ \\
\hline $500-430$ & $\begin{array}{l}\text { Myelin evolves and increases efficacy of } \\
\text { neural transmission } \\
\text { Rhodopsin evolves from cone opsin and rod } \\
\text { bipolar cells evolve (possibly from rod } \\
\text { photoreceptors) } \\
\text { Highly contractile iris evolves } \\
\text { Refractive capabilities of the lens improved } \\
\text { Intraocular eye muscles evolve, allowing } \\
\text { accommodation of the lens } \\
\text { Retina contains both rods and cones and has } \\
\text { more efficient processing capability }\end{array}$ & $\begin{array}{l}\text { Eye has strong image-forming capabilities, } \\
\text { including for adjusting the amount of } \\
\text { incoming light and accommodating the lens } \\
\text { to focus at different distances }\end{array}$ & $\begin{array}{l}\text { Yes. Similar to the eyes of many modern } \\
\text { fishes }\end{array}$ \\
\hline$<430$ & $\begin{array}{l}\text { In tetrapods, the lens becomes elliptical to } \\
\text { compensate for added refractive power of } \\
\text { the cornea in air } \\
\text { Eyes become specialized in different groups } \\
\text { according to different conditions (e.g., } \\
\text { nocturnal vs. diurnal, predators vs. prey, etc.) }\end{array}$ & $\begin{array}{l}\text { Eyes as found in modern amphibians, } \\
\text { reptiles, mammals, and birds }\end{array}$ & Yes. You are reading this page \\
\hline
\end{tabular}

This hypothesis is based on several independent lines of evidence, including analyses of genes and proteins, comparisons of living species with differing degrees of eye complexity, and information regarding the development of eyes in embryonic vertebrates. For a detailed discussion, see Lamb et al. (2007) and for a less technical review see Lamb et al. (2008).

Mya Million years ago

${ }^{\mathrm{a}}$ See Ward et al. (2008) 
Table 2 Examples of some of the direct and indirect evolutionary processes that may be involved in the evolution of eyes

\begin{tabular}{|c|c|}
\hline Process & Examples from eye evolution \\
\hline Direct adaptive evolution & $\begin{array}{l}\text { Gradual evolution of lens crystallin concentrations resulting in evolution of graded refractive } \\
\text { index lenses in aquatic animals }\end{array}$ \\
\hline \multicolumn{2}{|l|}{ Exaptation } \\
\hline $\begin{array}{l}\text { One structure has one function and takes on or } \\
\text { switches to a new function in a new } \\
\text { environment }\end{array}$ & $\begin{array}{l}\text { The cornea, which has no refractive capacity in water, became the primary focusing } \\
\text { structure after tetrapods moved onto land } \\
\text { The lens became far less important in image formation in terrestrial vertebrates and became } \\
\text { specialized for accommodation instead }\end{array}$ \\
\hline $\begin{array}{l}\text { One structure has one function but becomes } \\
\text { modified enough to allow a shift in function }\end{array}$ & $\begin{array}{l}\text { Circadian organ in early chordates became modified sufficiently that it became capable of } \\
\text { visual functions } \\
\text { An early protective, transparent layer of cells became sufficiently thickened and invaginated } \\
\text { that it could begin serving as an early lens }\end{array}$ \\
\hline $\begin{array}{l}\text { Two structures perform the same function but } \\
\text { become differently specialized }\end{array}$ & $\begin{array}{l}\text { Though both cell types were probably found in the distant bilaterian ancestor, ciliary } \\
\text { photoreceptors became the dominant type in vertebrates whereas rhabdomeric } \\
\text { photoreceptors came to predominate in most other animals (see also duplication and } \\
\text { divergence) }\end{array}$ \\
\hline A vestigial structure takes on new function & $\begin{array}{l}\text { In vertebrates, rhabdomeric photoreceptors lost their microvilli and became retinal ganglion } \\
\text { cells that function in circadian entrainment rather than in vision }\end{array}$ \\
\hline Duplication and maintenance of repetition & $\begin{array}{l}\text { The compound eyes of arthropods are composed hundreds or thousands of repeated lens } \\
\text { eyes called ommatidia }\end{array}$ \\
\hline Duplication and divergence & $\begin{array}{l}\text { Opsin genes duplicated and diverged to become r-opsins and c-opsins, along with } \\
\text { specialization of rhabdomeric cells with r-opsins and ciliary cells with c-opsins } \\
\text { In certain taxa, duplications and diversification of opsins to respond to different wavelengths } \\
\text { of light allowed the evolution of color vision } \\
\text { The rod cells of vertebrates are derived from cone cells, both of which are derived from a } \\
\text { single ancestral ciliary photoreceptor }\end{array}$ \\
\hline Gene sharing & $\begin{array}{l}\text { Some lens crystallin proteins function both in the eye in light refraction and elsewhere in the } \\
\text { body for other functions (e.g., cellular stress response) }\end{array}$ \\
\hline Collage & $\begin{array}{l}\text { The first photopigment was formed by the combination of a preexisting light sensitive } \\
\text { molecule derived from vitamin A (which became retinal) with a preexisting G protein- } \\
\text { coupled receptor protein (which became the ancestral opsin) } \\
\text { The first "eye" arose by the combination of a photoreceptor cell with a pigment cell } \\
\text { During the evolution of complex camera-type eyes, various types of tissue that already } \\
\text { existed (e.g., blood vessels, nerves, muscles) were incorporated }\end{array}$ \\
\hline Scaffolding & $\begin{array}{l}\text { May apply to the evolution of phototransduction pathways or other relevant biochemical } \\
\text { systems, but more data are required }\end{array}$ \\
\hline Constraints, trade-offs, and historical contingency & $\begin{array}{l}\text { Trade-off between resolution versus brightness in pinhole camera eyes } \\
\text { Trade-off between visual acuity versus size of compound eyes } \\
\text { Inverted retina in vertebrates } \\
\text { A narrow range of available wavelengths of sunlight is perceived in most animals, probably } \\
\text { because eyes first evolved in water which filters most wavelengths }\end{array}$ \\
\hline Convergence & $\begin{array}{l}\text { Lenses, irises, and various other components of camera-type eyes emerged independently in } \\
\text { vertebrates and cephalopods }\end{array}$ \\
\hline Parallel evolution & $\begin{array}{l}\text { The same developmental or other genes may have been independently co-opted in different } \\
\text { lineages (though homology is also a possibility) }\end{array}$ \\
\hline
\end{tabular}

As noted, photopigments are membrane-bound proteins, which means that maximizing the number of molecules that can be contained within specialized light-sensitive cells involves increasing the surface area of the cell membranes. This has generally been accomplished in two ways, thereby defining two distinct categories of photoreceptors: (1) in rhabdomeric photoreceptor cells, membrane area is increased through the growth of projections of the upper end of the membrane (apical microvilli), (2) in ciliary photoreceptor cells, a fold of the ciliary membrane is used for increasing the amount of photopigment that can be held. These two cell types differ in other important ways, including in the type of opsin they contain (rhabdomeric or r-opsin, and ciliary or c-opsin, respectively) and the mechanism by which interactions with photons are transduced into electrical information (Arendt and Wittbrodt 2001; Arendt 2003; Nilsson 2004; Fig. 11).

It was traditionally thought that rhabdomeric photoreceptors were found only in protostomes whereas the ciliary type 


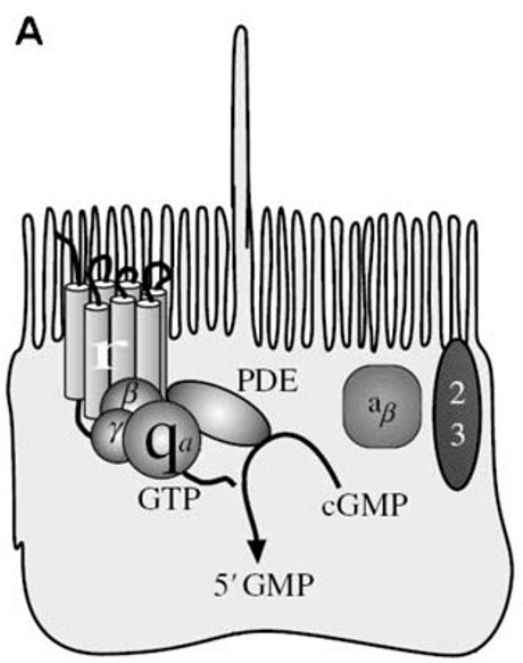

Fig. 11 The two photoreceptor types found in animals. A Rhabdomeric photoreceptors, which use extensions of the membrane (apical microvilli) to increase the amount of photopigment (r-opsin) that they can contain. Rhabdomeric photoreceptors are the predominant type found in protostomes (most invertebrates). B Ciliary photoreceptors, which make use of a modified ciliary membrane to increase the surface area available for storing photopigment (c-opsin). Ciliary photoreceptors are the main type

was restricted to deuterostomes. However, further research has identified species containing both types. The polychaete worm Platynereis dumerilii, for example, has rhabdomeric photoreceptors in both its larval eyes and in its two pairs of adult eyes as would be expected for a protostome. However, it was also recently discovered to have ciliary photoreceptors in its brain, complete with c-opsins and regulatory genes more similar to those of vertebrates than to those associated with its rhabdomeric photoreceptors. These ciliary cells are not involved in vision but apparently serve a circadian function (Arendt et al. 2004).

The box jellyfish Tripedalia cystophora provides a second example. It has 24 eyes, including two pit-shaped and two slit-shaped pigment cups and two camera-type lens eyes positioned at right angles to one another on each of four specialized sensory clubs called rhopalia (Nilsson et al. 2005; Kozmik et al. 2008a, b; Fig. 4). The jellyfish camera-type eyes appear to use ciliary opsin as the photopigment and melanin as the shielding pigment - both as in vertebrates though its lens protein is distinct from those of other animals (Kozmik et al. 2008a, b; as an aside, it is somewhat enigmatic that complex camera-type eyes complete with tiny, spherical, graded index lenses and, in the lower eye, an iris would occur in these animals, as they are not connected to a brain and are not arranged in such a way as to generate a sharp image in any case; Nilsson et al. 2005; Wehner 2005).

Humans, like other vertebrates, make use of ciliary photoreceptors with c-opsins in their retinas for image processing

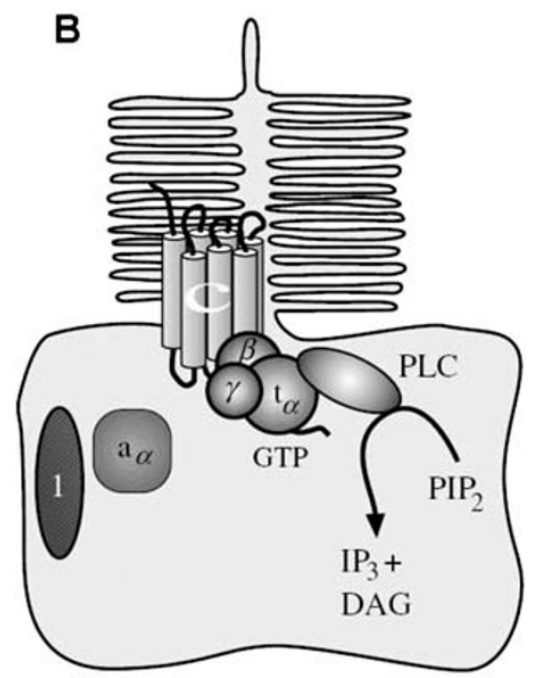

observed in deuterostomes (vertebrates, echinoderms, and relatives). The two cell types differ in their phototransduction pathways and in the electrical responses that result. It is thought that both cell types were already present in the ancestor of all bilaterian animals, having been derived from one ancestral photoreceptor type (Fig. 14). From Arendt and Wittbrodt (2001), reproduced by permission of The Royal Society and D. Arendt

(see Kolb 2003 for a review of retina morphology and function). However, a second category of photoreceptor was discovered in 1991, in the form of a subset of retinal ganglion cells containing a photopigment dubbed melanopsin. It is now recognized that these cells are remarkably similar to the rhabdomeric cells of invertebrates and that melanopsin is similar to r-opsin (see Van Gelder 2007 for review). Though they are located within the retina, these cells do not function in image formation; instead, they appear to serve a circadian function. It is for this reason that some blind people lacking rods and cones can nonetheless respond to day-night cycles (Van Gelder 2007; Zaidi et al. 2007).

The cases of Platynereis, Tripedalia, and humans suggest that most animals will turn out to exhibit both types of photoreceptor cells, or at least that they had both at some stage in their ancestry (Plachetzki et al. 2005). They also suggest that both cell types were present in the common ancestor of all bilaterally symmetrical animals (the Urbilaterian; Arendt and Wittbrodt 2001; Arendt et al. 2004). In particular, these cells are thought to derive from a common ancestral cell via duplication (or furcation sensu Oakley et al. 2007) and divergence (making them "sister cell types"; Arendt 2003), with protostomes eventually using the rhabdomeric type in their eyes and deuterostomes using the ciliary type. The reason for this distinction is not clear, and may represent little more than a quirk of history.

There is also evidence that duplication and divergence have occurred within cell types. Not only are the rod cells 
of the vertebrate retina thought to be derived from cone cells within the ciliary type (Okano et al. 1992; Kawamura and Tachibanaki 2008), but so too are the bipolar cells in the retina (Lamb et al. 2008). Similarly, it has been suggested that the descendants of rhabdomeric photoreceptors include not only the retinal ganglion cells but also the horizontal and amacrine cells (Arendt 2003). If correct, then this would mean that the retina at large is derived from two ancestral types of photoreceptors, which themselves are derived from a single type that existed long before the evolution of vision.

\section{Lenses $^{7}$}

Sharp image formation requires that incoming light rays be redirected so that they converge on the photoreceptors of the eye. There are various ways by which this can be accomplished, for example, by either reflecting or refracting light. Animals with camera-type eyes use the latter mechanism by placing material of a refractive index different from the external medium in between the source of light and the retina (Fig. 5).

It is not difficult to see how gradual changes (i.e., direct adaptive evolution) could refine the function of lenses once they appeared in very rudimentary form. As Land and Nilsson (2002, p 58) explained,

a small blob of jelly or mucus, with a refractive index somewhat higher than the surrounding water, placed in the pupil of the eye, will converge entering rays slightly, and this in turn will reduce the width of the blur circle on the retina without requiring a decrease in pupil diameter. The process of improvement could continue until the 'lens' converged the light to a point on the retina, at which stage the transformation to an image-forming eye would be complete.

Any substance with an appropriately different refractive index can improve focus in an eye lacking a lens: as Dawkins (1996) showed, even a bag of water or glass of white wine can enhance the image formed by a pinhole camera. That a "blob of jelly" could be functional is demonstrated by the fact that such a simple lens, which converges light but is not sufficiently effective to form an image, exists in snails of the genus Helix (Land and Nilsson 2002; Fig. 10). The lenses of cephalopod mollusks or vertebrates are far more sophisticated and are capable of focusing light sharply. They also exhibit graded refractive indices, lower at the edges and higher

\footnotetext{
${ }^{7}$ Discussions of the structure and/or evolution of lenses, corneas, and crystallins are provided by Tomarev and Piatigorsky (1996); Piatigorsky (1998, 2007, 2008), Land and Nilsson (2002), Bloemendal et al. (2004), and Jonasova and Kozmik (2008).
}

in the centre, which correct for spherical aberration (Land and Nilsson 2002; Fig. 7). Nevertheless, the difference between the lens of Helix and that of Octopus is one of degrees, easily connected through incremental steps. The origin of the earliest lenses, on the other hand, can only be understood as a result of indirect evolution.

As Lamb et al. $(2007,2008)$ explain, the tissues that form the lens in vertebrate eyes did not always have this function. At first, they probably served a developmental role by triggering the invagination of the eye vesicle, later thickening and becoming transparent, and eventually becoming sufficiently modified in this regard to provide a small amount of focusing power. Certainly this series of changes does occur within the early development of vertebrate embryos (Cvekl and Piatigorsky 1996; see Fig. 12), though of course one must be very cautious not to overstate any similarities between ontogeny (development) and phylogeny (evolutionary history). One of the major ways that such rudimentary lenses became specialized for their new imaging function was by the accumulation of refractive proteins known as crystallins within the cells of which they are composed. All crystallins have in common the fact that they are globular, water-soluble proteins capable of refracting light either alone (monomers) or in combinations of various numbers of molecules (dimers, tetramers, or more complex aggregates), can be densely packed, and remain stable for the lifetime of the organism (Piatigorsky 2007).

Unlike opsins in the retina, crystallins are not descended from a common ancestral protein. Rather, these have been coopted from a wide range of preexisting proteins in different lineages, especially from common stress proteins or metabolic enzymes (Fig. 13). For this reason, True and Carroll (2002) suggest that crystallins represent "by far, the classic and best studied cases of co-option in animal evolution." Notably, many lens crystallins are not only similar but identical to proteins that serve other functions in the eye and elsewhere in the body. That is, they provide not just an example of cooption but of gene sharing, such that only comparatively minor changes - such as in the amount and location of gene expression of existing proteins - was required to produce the first simple layers of tissue capable of refracting light (Piatigorsky 2007, 2008). Once this occurred, gradual natural selection could have refined them and the tissues in which they reside to produce increasingly efficacious lenses.

Vertebrate lens crystallins consist predominantly of representatives from two protein groups, the $\alpha$-family and the $\beta \gamma$ superfamily. The $\alpha$-family crystallins in the lens are derived from chaperone proteins and include two major forms that have emerged through duplication and divergence: $\alpha \mathrm{A}$ is largely lens-specific while $\alpha \mathrm{B}$ is expressed elsewhere in the body, such as in the heart, muscles, and brain. Both still function in a chaperone capacity in addition to their role in 


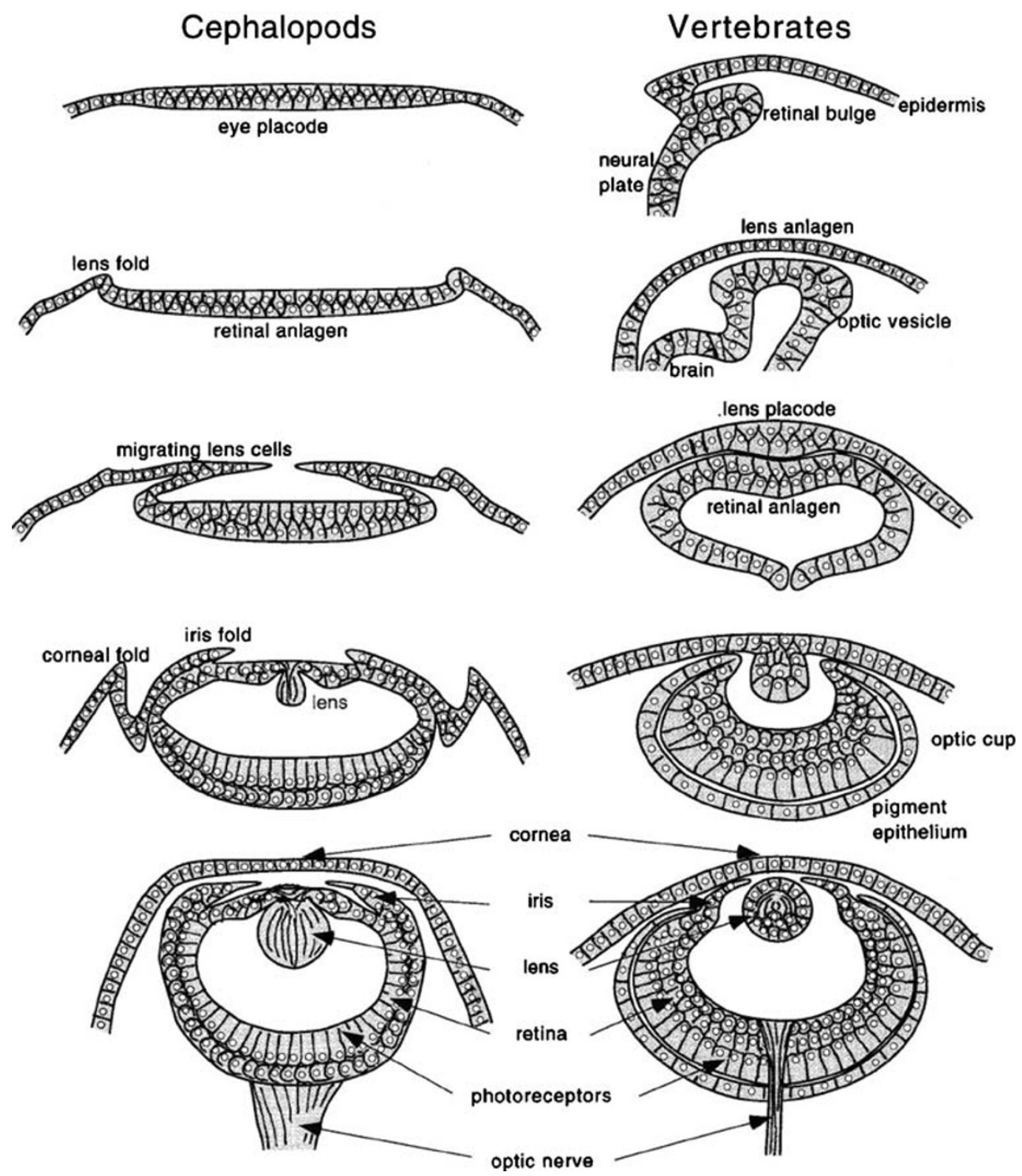

Fig. 12 A schematic representation of eye development in cephalopod mollusks (e.g., squid) and vertebrates: these represent the series of stages that occur during the development of individual embryos (proceeding from top to bottom) and should not be confused with the historical path followed during eye evolution in either mollusks or vertebrates. The different evolutionary and developmental pathways followed by cepha-

image formation (Bloemendal et al. 2004). The $\beta$ and $\gamma$ crystallins are each also represented by multiple gene copies, only some of which are expressed exclusively in the lens. However, in this case the functions of the copies expressed outside the eye remain to be determined (Bloemendal et al. 2004; Piatigorsky 2007).

One of the key questions in the evolution of the vertebrate lens relates to how these genes could first have come to be expressed at a high level in the tissue that evolved into the lens, such that there could then be selection on their arrangement, abundance, and other properties to enhance their refractive function. This question was answered in part in a lopods versus vertebrates result in eyes that are superficially similar (both are complex camera-type lens eyes) but with some major differences. Notably, the optic nerve does not pass through the retina in cephalopods, meaning that they do not have blind spots. From Harris (1997), reproduced by permission of the National Academy of Sciences of the USA

recent study by Shimeld et al. (2005), who showed that the sea squirt Ciona intestinalis (a chordate, specifically a urochordate, but not a vertebrate) possesses a version of a $\beta \gamma$ crystallin gene that is expressed preferentially in larval lightsensing structures called ocelli, even though these consist of only a single pigmented photoreceptor cell. It therefore must have a function that is associated with visual systems but not light refraction because Ciona ocelli do not have lenses. The regulatory genes that produce this tissue-specific expression are very similar to those that direct crystallin expression in vertebrate lenses: in fact, one can transfer the gene from Ciona to a frog, and frog lenses will be produced (Shimeld 


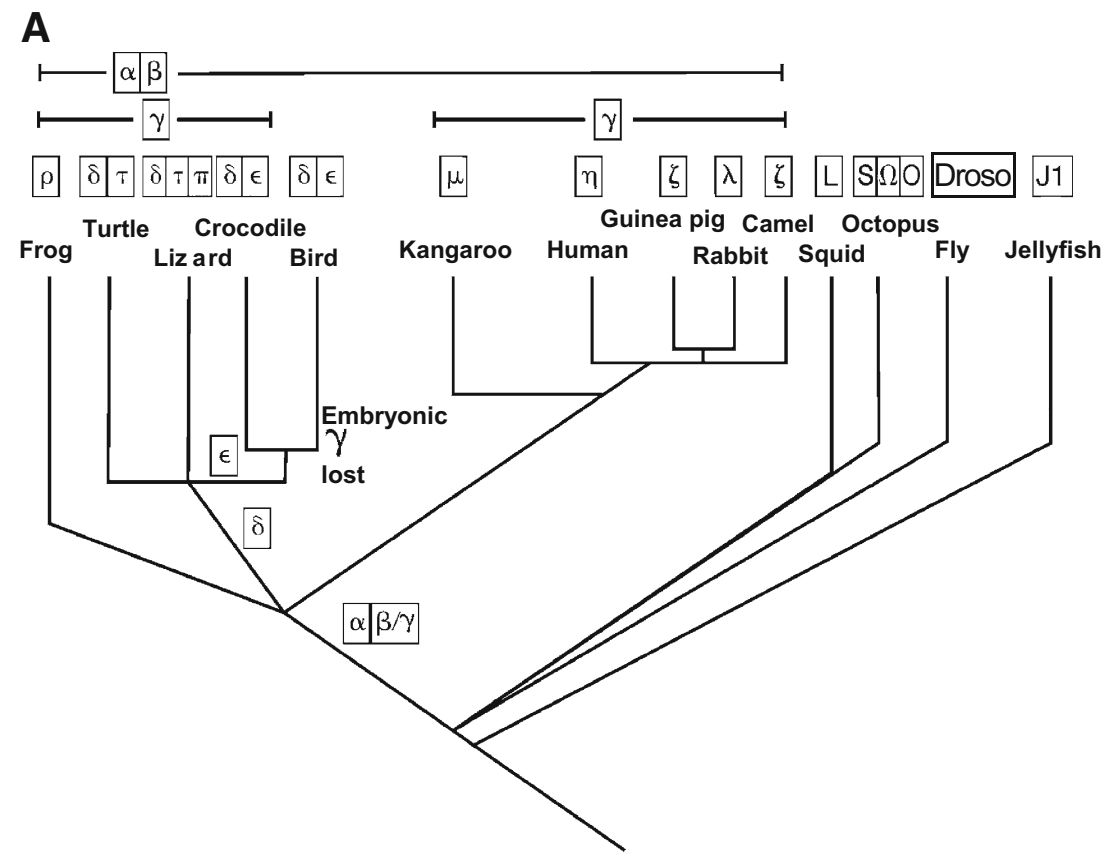

B

\begin{tabular}{|c|c|}
\hline Crystallin & Ancestral protein function \\
\hline$\alpha$ & Small heat shock protein \\
\hline$\beta / \gamma$ & Related to bacterial stress protein \\
\hline$\rho$ & NADPH-dependent reductase \\
\hline$\delta$ & Arginosuccinate lysase \\
\hline$\tau$ & $\alpha$ enolase \\
\hline$\pi$ & Glyceraldehyde phosphate dehydrogenase \\
\hline$\epsilon$ & Lactate dehydrogenase \\
\hline$\mu$ & Similar to bacterial ornithine deaminase \\
\hline$\eta$ & Aldehyde dehydrogenase \\
\hline$\zeta$ & Alcohol dehydrogenase \\
\hline$\lambda$ & Hydroxyacyl-CoA dehydrogenase \\
\hline $\mathrm{L}$ & Aldehyde dehydrogenase \\
\hline $\mathrm{S}$ & Glutathione-S-transferase \\
\hline$\Omega$ & Aldehyde dehydrogenase \\
\hline $\mathrm{O}$ & Similar to yeast TSFI \\
\hline Droso & Insect cuticle protein \\
\hline J1 & Similar to chaperonin / 60kd hsp \\
\hline
\end{tabular}

Fig. 13 Molecular co-option in the evolution of lens crystallin proteins. The $\alpha, \beta$, and $\gamma$ crystallins are ubiquitous among vertebrates, though the embryonic $\gamma$ crystallin has been lost in birds. Other crystallins are shown for the specific taxa in which they have been found, and this may not reflect their overall distribution among animals (A). Each of these crystallins is similar to another protein with a different function (B), suggesting that it was co-opted from an existing protein in a new role in refracting light in the eye. In fact, many crystallin proteins are expressed in tissues besides eye lenses where they carry out additional functions unrelated to vision (see Piatigorsky 2007). From True and Carroll (2002), reproduced by permission from the Annual Review of Cell and Developmental Biology, Volume 18 (C2002 by Annual Reviews www. annualreviews.org 
et al. 2005). This suggests that both the ancestral $\beta \gamma$ crystallin gene (perhaps in only one copy) and the regulatory sequences that influence where it is expressed already existed in a chordate ancestor prior to the evolution of lenses in vertebrates and were co-opted into this new role.

An independent example of this process was recently highlighted in an elegant study of squid lenses by Sweeney et al. (2007). In cephalopods, the lenses include only one type of crystallin, S-crystallin, which was derived by gene duplication and divergence from the liver enzyme glutathione S-transferase. The major difference between the two copies is that the Scrystallin sequence includes an exon (protein-coding region) that the liver enzyme gene does not, with the result that the crystallin protein exhibits an extra loop in its three-dimensional structure. This loop turns out to be functionally significant in the lens, and there is evidence that it began small and was accentuated by gradual selection as the crystallin took on its new visual function (Sweeney et al. 2007). Thus, the history of the squid lens includes gene duplication and divergence, smallscale mutation and natural selection, regulatory mutations, and co-option (Oakley 2007), all of which left tell-tale traces that are now being uncovered by careful scientific study.

\section{Corneas}

Refraction occurs when the velocity of a light wave changes as it travels through different media. The camera-type eyes of cephalopods and vertebrates evolved in water, which has a refractive index about the same as the fluid inside the eye. As a consequence, there is very little refraction of light as it enters the eye from the surrounding aqueous medium. The situation became quite different for the vertebrates who moved onto land, because the refractive index of air is very different from that of eye fluid, meaning that passage into the eye through the cornea itself generated significant refraction. In fact, whereas the cornea has little or no focusing function in aquatic animals, it may contribute as much as $70 \%$ of the light refraction in terrestrial vertebrate eyes (Land and Nilsson 2002). Thus, movement into a new environment led to a major functional shift in the cornea from a largely protective role to a visual one, for which it then became secondarily adapted (e.g., by becoming curved ${ }^{8}$ ). This, in turn, meant that the lens was largely obsolete for the major refractive function - in fact, at first it would have been redundant to the point of overfocusing - and in terrestrial vertebrates it became co-opted for a role in accommodation (focusing at different distances) which it accomplished by becoming flattened and deformable (or, in the case of nocturnal animals, especially large; Land and Nilsson 2002). Thus, indirect evolution,

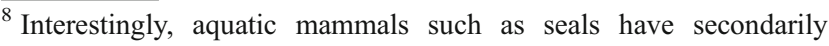
reverted to possessing flat corneas and spherical lenses like those of fishes (Land and Nilsson 2002).
}

especially exaptation and secondary adaptation, has played a significant role in the evolution of corneas and lenses as they exist in modern vertebrates.

Given that corneas rather than lenses now serve the primary role of refraction in many terrestrial vertebrates, it is interesting to consider whether they share any similarities to lenses at the molecular level - in particular, whether corneal crystallins have a similar evolutionary history to crystallins found in lenses. Although the situation is not as clear (in part because a visual function of corneal crystallins has not yet been established; Piatigorsky 2007), there is evidence that corneal crystallin evolution does indeed exhibit a history of duplication, cooption, and gene sharing. For example, the corneal crystallins of mammals are the same as an active aldehyde dehydrogenase class 3 enzyme (which functions in detoxification and may protect against UV damage), whereas those of birds are similar to peptidyl prolyl cis-trans isomerase (Cuthbertson et al. 1992; Piatigorsky 2007). Some corneal crystallins turned out to be the same as those in the lens, including a glutathione Stransferase derivative in the squid cornea. Recent studies of fishes and frogs have confirmed similar patterns of gene co-option. In fishes, a series of proteins derived by gene duplication from an ancestral gelsolin gene has become differentially expressed in different tissues: some primarily in the cornea, some in the cornea, lens, brain, and heart, and others in tissues other than these (Jia et al. 2007; Piatigorsky 2007). In frogs, which are amphibious and, therefore, have eyes adapted to vision both on land and in the water, the same proteins have been recruited in the cornea as in the lens (Krishnan et al. 2007). Overall, then, the evolution of the cornea appears to have been similar to (and perhaps predated; Piatigorsky 2007) the evolution of lenses in terms of the taxon-specific co-option and/or gene sharing of crystallin genes.

\section{How Many Times Have Eyes Evolved?}

The term "homology" can be defined as "the presence of the same feature in two organisms whose most recent common ancestor also possessed the feature" (Hall 2007). The counterpoint to "homology" is "homoplasy" (often also taught as "analogy"), which refers to similarities among species that are not due to the inheritance of the same trait from a common ancestor. ${ }^{9}$ Obviously, the question of how many times a particular feature has evolved is predicated on a clear distinction between homology and homoplasy. ${ }^{10}$ As Hall (2007)

\footnotetext{
${ }^{9}$ For historical reviews of the concepts of "homology," "analogy," and "homoplasy," see Hall (1994, 2003) and Panchen (1994, 1999). For a less technical discussion of homology and homoplasy, see Thanukos (2008).

${ }^{10}$ Alternatively, the question can be framed in a phylogenetic sense as being between "monophyly" (all species with the feature descend from a common ancestor with the feature) or "polyphyly" (species with the feature have evolved independently in separate lineages; Piatigorsky 2008).
} 
noted, "homology is the persistence of similarity" whereas "homoplasy is the recurrence of similarity". Yet, as is typical for most questions in the complex world of biology, an unambiguous line between homology and homoplasy is not so easy to draw.

First, one must consider the possible causes of homoplasy, two of which are convergence, which reflects the independent evolution of a similar feature using different genetic and developmental systems, and parallel evolution, the evolution of similar features that occurs independently but uses the same underlying systems. ${ }^{11}$ Thus, already the question is complicated by the fact that a homoplasious organ can evolve independently from the same starting point and using the same genes. Some authors consider the sharing of the same developmental genetic systems as a form of "deep homology" (e.g., Shubin and Marshall 2000; Rutishauser and Moline 2005). Nielsen and Martinez (2003) proposed the term "homocracy" for organs whose development is governed by homologous genes. Second, the designation of a feature as homologous versus homoplasious is dependent on the scale at which the comparison is made (Hall 2003; Rutishauser and Moline 2005). For example, the last ancestor shared by all modern birds was endothermic ("warm-blooded"), as was the last shared ancestor of all modern mammals, meaning that endothermy is homologous within both birds and mammals. However, the most recent ancestor common to both birds and mammals was not endothermic, which means that endothermy is homoplasious when these groups are compared with each other. Third, it is clear that a distinction can be drawn between a complex feature as a whole and the components of which it is made with regard to homology versus homoplasy. As an example, it is often correctly noted that the wings of birds and bats are homoplasious, given that the distant ancestor from which they are both descended (which was neither a mammal nor a bird) did not fly. On the other hand, the limbs of all tetrapods share a fundamental bone structure that has been inherited from an early common ancestor, meaning that the limbs of which bird and bat wings are constructed are homologous (Rutishauser and Moline 2005). These are also homologous with the bones of human arms, dog legs, and whale flippers because homology is defined on the basis of shared inheritance, not function (Wagner 2007).

Overall, it is debatable whether a dichotomy exists between homology and homoplasy; some authors have argued that instead these represent extremes on a continuum of degrees of modification (e.g., Hall 2003, 2007). In this sense, the question of whether a complex organ as a whole has evolved once or many times may be unanswerable. Rather, it is often much more useful to discuss the components of the organs

\footnotetext{
${ }^{11}$ A third cause of homoplasy, reversal, is not covered here. See Hall (2003, 2007).
}

themselves or the genetic, biochemical, cellular, and developmental systems that underlie their production and function, and to explore the extent to which these, rather than the complex organs per se, are shared via common descent among groups. It is within this context that one must consider the question of how many times "eyes" have evolved.

In their classic review of eye diversity and evolution, Salvini-Plawen and Mayr (1977) noted that "it requires little persuasion to become convinced that the lens eye of a vertebrate and the compound eye of an insect are independent evolutionary developments." Even within a single eye type, for example the camera-type lens eyes of vertebrates versus those of cephalopods, it is obvious that there has been substantial convergent evolution at the level of the organ as a whole. Human and squid eyes are constructed from different tissues, exhibit different morphological organization of the retina and other features, and use different photoreceptors, opsins, and crystallins (Land and Nilsson 2002; Sweeney et al. 2007; Fig. 12). Moreover, the distribution of eyes across the one third of phyla that have them makes it unlikely that they existed in any complex form in the ancestor of all animals because this would require that they have been lost in an improbably large number of lineages (e.g., Land and Nilsson 2002). Similar phylogenetic analyses even suggest that eyes have evolved independently within some taxa (e.g., ostracod crustaceans; Oakley and Cunningham 2002). Thus, considerations of the morphological differences in eyes and photoreceptors and their occurrence in divergent phyla speak strongly in favor of homoplasy. This led Salvini-Plawen and Mayr (1977) to provide an oft-cited estimate in which eyes have evolved independently at least 40 times and perhaps 65 times or more.

Modern information derived from many lines of evidence, including comparative morphology, molecular biology, phylogenetics, and developmental biology, clearly shows that eyes are the product of a complex evolutionary history. At the same time, the combination of data from these divergent lines of inquiry has tended to blur rather than resolve the long-standing puzzle of how many times eyes have evolved (e.g., Arendt and Wittbrodt 2001; Arendt 2003; Oakley 2003; Fernald 2004a; Nilsson 2004). Whereas "eyes," strictly defined as complex visual organs, clearly have arisen independently in different lineages, the ancestral opsins and photoreceptors from which all modern eyes are derived are thought to have been present in the last common ancestor of all bilaterians, thereby making them homologous (Arendt and Wittbrodt 2001; Arendt 2003; Fig. 14). It is also possible that vertebrates and jellyfishes inherited their similar opsins and photoreceptors from an even more distant common ancestor, though it has been argued that the intriguing similarities between them reflect independent recruitment of the same genes (i.e., parallel evolution) rather than homology (Kozmik et al. 2008a). The possibility that vertebrate retinal ganglion cells and invertebrate rhabdomeric 


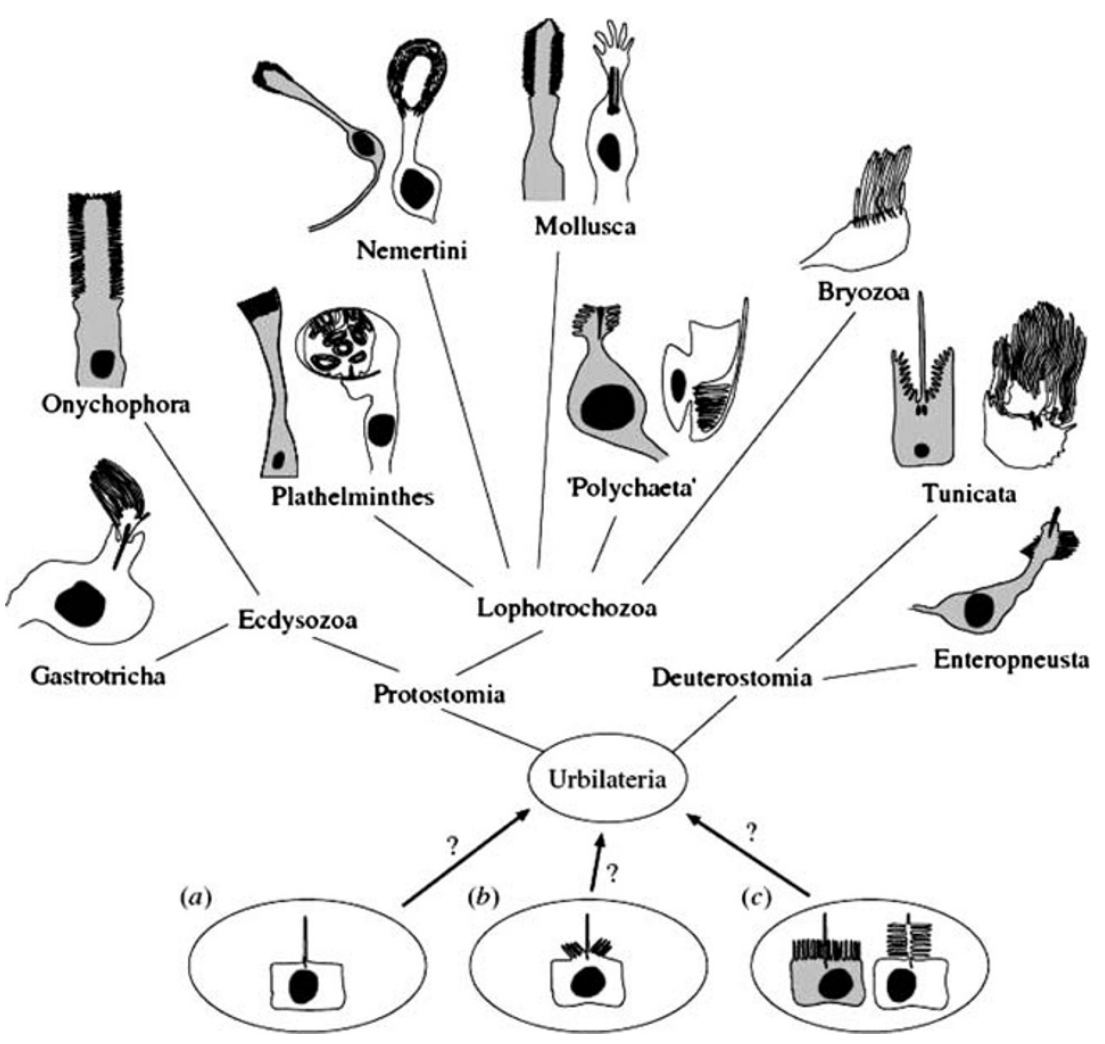

Fig. 14 The current distribution and origin of rhabdomeric (dark gray) and ciliary (white) photoreceptor cells among animals (see also Fig. 11). These are thought to have descended from cells already present in the last common ancestor of all bilaterally symmetrical animals (the Urbilaterian). It is thought that ciliary and rhabdomeric photoreceptor cells are descended from a single ancestral cell type,

photoreceptors represent examples of parallel evolution rather than homology also has been raised, though this is not a common interpretation (Nilsson 2004, 2005).

In any case, most current arguments in favor of eye homology are based not on comparisons of eyes or even photoreceptors, but of genes - specifically, those involved in regulating eye development. In 1994, it was discovered that genes that had been known to cause a loss of eyes when defective in flies (eyeless), mice (small eye), and humans (Aniridia) are, in fact, highly conserved versions of the same regulatory gene: Pax6 (Quiring et al. 1994). The following year, Halder et al. (1995a) manipulated the expression of the eyeless gene in flies so that it was active in tissues other than where it normally functions, with the result that eyes formed on the wings, the legs, and the antennae. Not only this, but Halder et al. (1995a) showed that the Pax6 gene from mice could also induce the generation of eyes in flies - but not mouse eyes, fly eyes (Fig. 15). Similarly, it was shown that ectopic expression of Pax 6 would induce the production of eye lenses in non-eye locations in frogs (Altmann et al. 1997; Chow et al. 1999). Observations such as these led to the conclusion that Pax6 is a "master control gene" responsible for eye formation and that it has served this role though there is some ongoing debate as to whether the Urbilaterian possessed (a) a ciliary precursor type from which both are derived, (b) a dual ciliary or rhabdomeric precursor that later diverged into two types, or (c) both ciliary and rhabdomeric cells that had already diverged earlier in animal evolution. From Arendt and Wittbrodt (2001), reproduced by permission of The Royal Society and D. Arendt

at least since the last common ancestor of insects and vertebrates. Combined with the notion that photoreceptors also were present in the urbilaterian, it was suggested that "eyes", defined minimally as a pigment cell and an opsincontaining photoreceptor cell regulated by a version of Pax6, evolved once, with all subsequent eyes arising through tinkering and elaboration of this ancestral system (Halder et al. 1995b; Gehring and Ikeo 1999; Gehring 2001, 2004, 2005; see Kozmik 2008 for discussion).

It may seem reasonable to conclude, therefore, that eyes simply exhibit deep homology with regard to their underlying photoreceptors, photopigments, and regulatory genes but are homoplasious in terms of their crystallins and overall organization. Life, however, is rarely ever this simple. Thus, it has also been discovered that Pax6 is not the only major gene involved in eye development (in flies, there is a network of seven such genes; Kumar 2001; Gehring 2004, 2005). Moreover, Pax6 is involved in many functions besides eye development, including in brain, nose, and pancreas development in mice. It even regulates some aspects of development in nematodes which lack visual organs altogether (Hodin 2000; Piatigorsky 2008). Therefore, the gene itself may be homologous, but this would not 


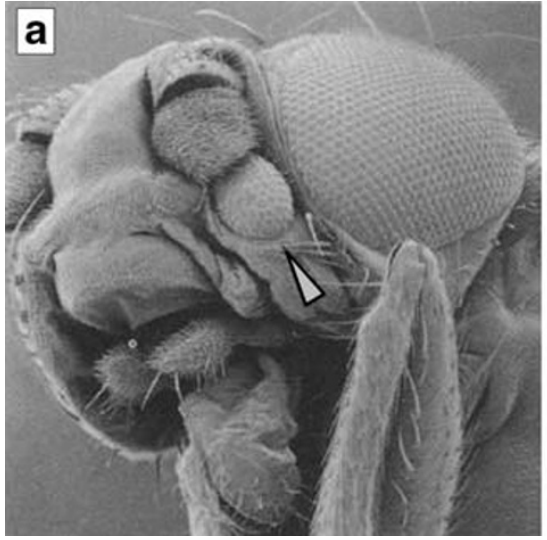

Fig. 15 Eyes induced to develop in unusual locations in a fly (Drosophila), such as on the head near the normal eye, on the antenna, and next to the wing (arrows) by experimentally expressing the eyeless (Pax6) gene. Using the Pax6 gene from a mouse has a similar

make eyes homologous if its ancestral function was unrelated to the development of visual organs. As Kumar (2001) noted, "several of the eye-specification genes are expressed and are involved in the development of non-eye tissue, but we do not say that the eye is homologous to the brain or to muscles." It is even possible that Pax6 has been independently recruited for a role in guiding visual organ development in different lineages (i.e., by parallel evolution) because it is one of the few regulatory genes expressed "at the right place at the right time" during development that could be co-opted into this role in each lineage (Hodin 2000).

Overall, the question of whether "eyes" evolved once or many times remains an open one, though the available answers depend more than anything on definitions and levels of analysis. In fact, it may not be useful to consider complex organs in this way at all. Instead, it is more productive to focus on the components of eyes, which have evolved and been combined and modified in a variety of ways in different groups.

\section{Constraints and Historical Contingency}

Eyes represented one of the main examples of what Darwin (1859) called "organs of extreme perfection and complication". To be sure, many features of eyes appear to have been optimized within the limits imposed by optical principles (Goldsmith and 1990; Land and Nilsson 2002). However, while the eyes of many species are complex and effective, perfect they are not. In fact, they provide as strong an example of imperfection - in particular, imperfection due to history - as anything else. There are numerous suboptimal features of eyes at the best of times, and various ailments may arise because of the way eyes have been tinkered into existence by direct and indirect evolutionary processes. Detached retinas, angle closure glaucoma, macular degenera-

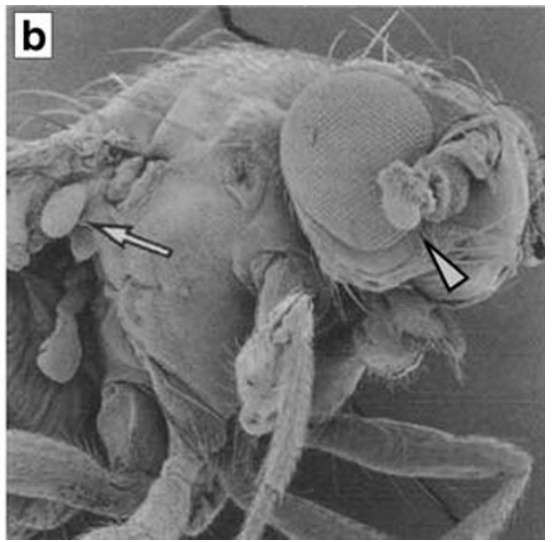

result, indicating that the gene in both species is very similar and was probably inherited in both lineages from a distant common ancestor. From Halder et al. (1995a), reproduced by permission of the American Association for the Advancement of Science

tion, and other breakdowns of eye function all fall within this category (see Novella 2008 for a review).

All eyes, not just those of humans, are influenced by historical contingency and constraints, and moreover once adaptation has begun down a particular path-for example, in the formation of a camera-type, compound, or pinhole eye - it can be very unlikely for evolution to reverse course and change to a different avenue. Natural selection has no foresight or objectives - it is simply the greater reproductive success of certain individuals relative to others in the population based on heritable traits that they happen to possess. If individuals with slight improvements in a particular kind of eye leave more offspring than individuals lacking this improvement, then this change will be favored regardless of whether it means another step up an alley that is partly blind.

Put another way, optimization is local rather than idealistic. The metaphor most often used in this sense is one of a mountain range consisting of "adaptive peaks" of varying heights. Insects provide a notable example of what can be considered climbing a "local adaptive peak," which may not be the highest but any movement off of which means a reduction in fitness. No doubt, eyes (along with other complex structures like wings) have contributed greatly to their enormous success, and it is not difficult to imagine even a moderately less effective eye being quickly eliminated from a population in any environment in which light is available. Yet, as well tuned as they now are, the compound eyes of insects are subject to fundamental physical constraints that prevent them from ever matching the visual acuity provided by camera-type eyes (Fig. 16). Whereas human eyes can resolve points that are $0.008^{\circ}$ apart, flies can distinguish points no less than $4^{\circ}$ apart (Kirschfeld 1976); as Nilsson (1989) put it, "one fruit fly would need to be closer than $30 \mathrm{~mm}$ to see another as anything other than a single spot." Similarly, the cephalopod mollusk Nautilus possesses a pinhole eye of 


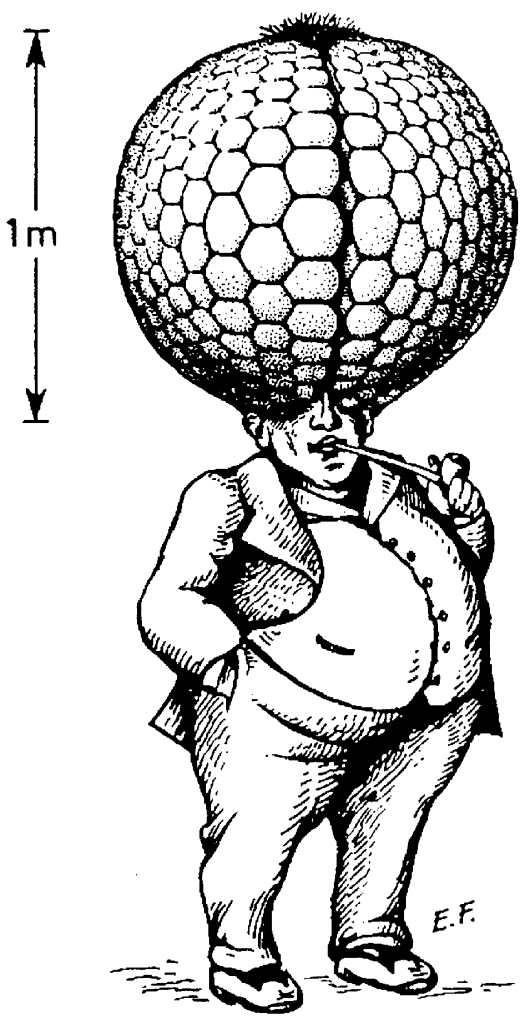

Fig. 16 Physical constraints on eye function. Although compound eyes have proven remarkably successful, they are fundamentally limited in their resolution by physical constraints. In order to exhibit the same resolution as is typical with camera-type lens eyes, a human being would require compound eyes a meter across and comprised of a million facets (only about 100 are shown for simplicity). From Kirschfeld (1976)

which further improvement is greatly restricted by a tradeoff between the resolution of an image and its brightness (Land and Nilsson 2002).

Likewise, the human eye is limited in many regards as compared to the eyes of other animals. Squid, for example, have retinas that are not inverted and are without a blind spot. The resolution of hawk eyes is about twice as high as that of humans, and there are many nocturnal animals capable of vision in far dimmer light than is conducive to human sight. Stomatopod crustaceans (mantis shrimps), which exhibit the most complex eyes thus far discovered, possess 16 morphologically distinct photoreceptor types and can see both UV and circular polarized light (Marshall et al. 2007; Chiou et al. 2008; Cronin and Porter 2008).

\section{Misconceptions About Complex Organ Evolution}

Although the exact history of any particular complex biological feature may never be fully worked out, biologists are confident that the mechanisms by which they arise can beand to a growing extent, are - understood. Yet, despite major accomplishments on both theoretical and empirical fronts, misconceptions regarding the evolution of complex organs remain common (including among those who accept evolution as historical reality) and prevent this understanding from extending more widely. Some of the most common of these are outlined in the following sections (see also Le Page 2008).

Misconception \#1 Supposed intermediate stages in the evolution of complex organs could not be functional.

This misconception is often expressed in the form of a question: "What good is half an X?", where X is any complex feature such as a wing or an eye. ${ }^{12}$ More generally, it is based on the assumption that a complex system missing some of its parts would be completely nonfunctional and therefore could not have evolved through less complex ancestral stages. Such an assumption is faulty for several reasons. First, the assumption that complex organs must be either perfectly functional or totally functionless is demonstrably false. For example, various components of the eye can be misshapen, misaligned, or even missing and yet vision is not totally lost. ${ }^{13}$ The same often holds in biochemical systems: for example, a heritable deficiency of Factor XII (Hageman factor) of the blood clotting cascade may have little effect on coagulation ability because other components of the system can compensate for its absence (Ratnoff and Margolius 1955). Second, whereas removal of some components may indeed render a biological system nonfunctional for its current role, it may still be functional in a different way. For example, the eyes of individuals missing rod and cone cells may still serve a circadian function (Zaidi et al. 2007). Again, this also applies to subcellular systems, as with the observation that a bacterial flagellum missing many of its parts is no longer useful for locomotion but can be used as a toxin injection apparatus (Pallen and Matzke 2006). Third, species exhibiting less complex but obviously functional versions of the same system often can be found. With eyes, there is a clear range in complexity from single photoreceptors to complex eyes of various types, all of which function in the organisms possessing them (Salvini-Plawen and Mayr 1977; Land and Nilsson 2002). What all of this shows is that biological features can exist, function, and be beneficial relative to alternatives - and, therefore, evolve by natural selectioneven when some components are only marginally effective or indeed lacking altogether. Again, the only requirement is

\footnotetext{
$\overline{12}$ The literal answer is that half an " $\mathrm{X}$ " is not a non-functional halfletter, it is either a forward slash $(/)$ or backslash $(\backslash)$ or a " $V$ " or caret $(\wedge)$, all of which work just fine for different functions. Of course, these are all modern characters and are not ancestors of the letter " $\mathrm{X}$ ", which was probably co-opted from the Greek chi.

${ }^{13}$ Case in point: the present author suffers from a trifecta of myopia, astigmatism, and strabismus, all only partially corrected with eyeglasses and rather unpleasant surgery, but he notes that this is still vastly preferable to no vision whatsoever!
} 
that less complex stages be functional for something, and not necessarily for their current function and that they be at least slightly better than existing alternatives in enhancing survival and reproduction.

Misconception \#2 Ancestral intermediates: either missing or still present.

The concept of ancestral intermediates (or transitional forms) is subject to misunderstanding in a variety of ways. On the one hand, it is sometimes suggested that stepwise evolution should leave behind millions of fossil intermediates that illustrate the evolution of a feature along a smooth gradation. The fact that only a miniscule fraction of individual organisms is preserved as fossils makes this an unreasonable expectation, especially in cases where evolutionary changes are relatively rapid. Notably, various complex eyes appear to have evolved during the comparatively short period of the Cambrian more than 500 Mya. On the other hand, there is sometimes a tendency to see "ancestral intermediates" in the wrong place, namely in comparisons of living species. Whereas some species do retain more primitive (ancestor-like) versions of particular organs and therefore provide information about how such simpler configurations could function, it is incorrect to compare modern species as though they represent actual steps in an evolutionary sequence of ancestors and descendants. In both cases, a better understanding of "tree thinking" can help to correct the misunderstanding (e.g., Gregory 2008c).

Misconception \#3 Biologists propose that complex organs arise "by chance."

The variation upon which natural selection acts is generated by mutation, and it is certainly the case that these accidents of inheritance occur randomly with respect to any consequences that they may have. It is also true that natural selection possesses no capacity for foresight and has no final objectives as it alters population characteristics from one generation to the next. It does not follow, however, that the evolution of complex organs occurs "by chance." By definition, natural selection is the non-random differential success of individuals on the basis of heritable variation and therefore the cumulative outcome of this process - adaptation - is the opposite of random chance.

Misconception \#4 All features of a complex organ are optimal.

Natural selection can lead to remarkably effective functional capabilities in complex organs. That it will do so in all cases is far from guaranteed, however. For a start, any optimization that does occur will proceed only as far as the limitations of the system will allow. Furthermore, functional improvement in one organ must take place within the context of tradeoffs with other systems. Finally, there must be an appropriate imposition of selective pressures by the environment, the necessary genetic variation, and a sufficiently flexible developmental program if significant change is to occur in the direction of improved function. Because organs are built by tinkering rather than design, their features are impacted by historical contingency and inevitably reflect holdovers of past states (Shubin 2007). The net result is that all complex organs represent a mixture of optimizations and imperfections, both of which are accounted for by their evolutionary history. Misconception \#5 Indirect evolution implies that various preexisting structures are assembled instantaneously into a new organ.

Indirect evolutionary processes such as shifts in function (exaptation) and the combining of existing structures (collage) play important roles in the origin of complex organs. However, this is sometimes misunderstood to imply that all components are (1) already in their final form when assembled together and (2) brought together simultaneously to form a new complex organ. In actuality, the addition of components to an evolving organ may occur in series (i.e., one at a time) and may involve a relatively poor fit at first. Again, the only criteria for such additions to be preserved by natural selection are that they must serve some function, and they must confer an advantage relative to alternatives within the population. Once combined, secondary adaptation may improve the integration of parts and may in the process enable other parts to be added, once again possibly resulting in a shift in function and beginning as a poor fit that is enhanced only later (Fig. 3). Thus, even indirect evolution is gradual in the sense that it proceeds in a stepwise fashion and requires no prohibitively improbable leaps.

Misconception \#6 Hypotheses about complex organ evolution cannot be tested.

Because they relate to unique events postulated to have occurred in the deep past, it is sometimes argued that hypotheses about the evolution of complex organs cannot be tested. It is a truism that the exact details of distant historical events cannot be known with absolute certainty. However, this does not mean that no conclusions can be drawn about them on the basis of supporting data (Cleland 2001, 2002). Interestingly, the fact that hypotheses about the evolution of complex organs can be tested is tacitly acknowledged by those who claim that a lack of a great many transitional fossils calls for a rejection of the hypothesis that complex organs evolved gradually - erroneous and based on false premises, to be sure, but a prediction nonetheless. Of course, biologists do make predictions regarding the characteristics of as-yetunknown fossil species in order to test hypotheses about evolutionary transitions. As a prime example, the transitional species Tiktaalik roseae, which possessed characteristics of both fishes and tetrapods, was recently discovered in rocks of the anticipated age as part of an explicit effort to test ideas regarding the evolutionary transition from water to land (Daeschler et al. 2006; Shubin et al. 2006). Aside from fossils, biologists also make use of molecular, genetic, anatomical, developmental, and cytological data to elucidate the evolution of complex organs, in some cases making very ex- 
plicit predictions in order to test their explanatory hypotheses (see, for example, the thorough list of testable predictions regarding vertebrate eye evolution by Lamb et al. 2007). Some of the extensive information resulting from these independent types of study has been reviewed here, though it should be noted that this relates to just one organ and covers but a fraction of the scientific literature on complex organ evolution.

Misconception \#7 An inability to explain every detail of a complex organ's history challenges the validity of evolutionary science.

Following in the tradition of Paley (1802) from two centuries ago, it is sometimes asserted that if a natural explanation is unavailable to account for an observation, then the only alternative is to assume a supernatural one. Such an assumption misses the obvious third option, and the one that drives scientific inquiry: that there is a natural explanation that is not yet known. Thanks to work carried out in pursuit of natural explanations, a great deal is now understood about the form, function, and probable origins of many complex biological organs and systems. That said, it should come as no surprise that these investigations do not provide detailed, unambiguous, step by incremental step reconstructions of events that in many cases occurred hundreds of millions of years ago. Of course, the same is true even of studies dealing with much more recent events, as in archeology, history, or forensics - in all cases, the important requirement is a convergence of several independent lines of evidence that point to the same conclusion. As discussed in this article, data from genetics, molecular biology, developmental biology, comparative anatomy, paleontology, and even medicine all point to a conclusion that eyes are the product of natural evolutionary mechanisms.

In any case, there is a broader misconception inherent in the claim that an incomplete recounting of a particular evolutionary outcome challenges the validity of evolution generally. This involves the common confusion surrounding the meanings of "fact" and "theory" in science and, in terms of historical sciences in particular, of "path" (Gregory 2008 b). That species are related by common ancestry is supported by an overwhelming body of evidence from many disciplines. In fact, no reliable observation has been made to refute this conclusion in more than 150 years. As a result, evolution - defined as a historical process of descent with modification - has long been accepted as a fact by the scientific community. Facts require explanations, however, and this is the job of evolutionary theory which includes, among other things, the mechanism of natural selection. Questions regarding a particular organ's unique evolutionary path (When did it appear? Did it evolve more than once?) or mechanism responsible for its origin (Adaptation? Exaptation?) do not bear on the fact that species are related by common descent, which has long been established using other evidence. As such, a current or even permanent inability to explain the origin of a specific feature in great detail with regard to path or even mechanism does not pose a challenge to the accepted fact that they were driven down some evolutionary path by some evolutionary processes - it merely poses a challenge to researchers to expand their efforts in the field, in the lab, and in the development of testable ideas.

\section{Concluding Remarks}

The origin of complex features is, quite obviously, a complex subject. The precise details of how, when, and how many times a particular biological organ has evolved may never be known with absolute certainty, but the great conceptual and empirical advances made over the past 150 years have provided a solid understanding of the processes involved. Complex organs do not come into being fully formed, but neither do they necessarily evolve through a direct series of incremental steps, each of which improves their efficacy for a single function. Theirs may be a complicated history involving not only direct adaptive evolution but also shifts to or additions of new functions and the juxtaposition of components that, themselves, may have been built up by these same historically contingent processes. The genes involved in the production of complex organ components may be co-opted from or shared with other systems, and may be inherited in common or recruited independently in different lineages. Finally, although natural selection may result in impressive levels of optimization for a given function, it is not the only mechanism at work-meaning that complex organs, no matter how intricate, exhibit the signs of having traveled a circuitous evolutionary path.

Acknowledgments I am grateful to Russell Fernald, Bob Gregory, Trevor Lamb, Todd Oakley, and Joram Piatigorsky for providing helpful comments that improved the manuscript.

\section{References}

Adami C. Reducible complexity. Science. 2006;312:61-3. doi:10.1126/science.1126559.

Altmann CR, Chow RL, Lang RA, Hemmati-Brivanlou A. Lens induction by Pax-6 in Xenopus laevis. Dev Biol. 1997;185:119 23. doi:10.1006/dbio.1997.8573.

Arendt D. Evolution of eyes and photoreceptor cell types. Int J Dev Biol. 2003;47:563-71.

Arendt D, Wittbrodt J. Reconstructing the eyes of Urbilataria. Philos Trans R Soc Lond B Biol Sci. 2001;356:1545-63. doi:10.1098/ rstb.2001.0971.

Arendt D, Tessmar-Raible K, Snyman H, Dorresteijn AW, Wittbrodt J. Ciliary photoreceptors with a vertebrate-type opsin in an invertebrate brain. Science. 2004;306:869-71. doi:10.1126/science.1099955. 
Arnold EN. Investigating the origins of performance advantage: adaptation, exaptation and lineage effects. In: Eggleton P, Vane-Wright RI, editors. Phylogenetics and ecology (Linnean society symposia volume 17). London: Academic Press; 1994. p. $123-68$.

Ayala FJ. Darwin's greatest discovery: design without designer. Proc Natl Acad Sci U S A. 2007;104:8567-73. doi:10.1073/pnas. 0701072104.

Bahar S. Evolution of the eye: lessons from freshman physics and Richard Dawkins. Biol Physicist. 2002;2:2-5.

Battelle BA. The eyes of Limulus polyphemus (Xiphosura, Chelicerata) and their afferent and efferent projections. Arthropod Struct Dev. 2006;35:261-74. doi:10.1016/j.asd.2006.07.002.

Bishop KL. The evolution of flight in bats: narrowing the field of plausible hypotheses. Q Rev Biol. 2008;83:153-69. doi:10.1086/587825.

Bloemendal H, de Jong W, Jaenicke R, Lubsen NH, Slingsby C, Tardieu A. Ageing and vision: structure, stability and function of lens crystallins. Prog Biophys Mol Biol. 2004;86:407-85. doi:10.1016/j. pbiomolbio.2003.11.012.

Bock G, Goode J. Tinkering: the microevolution of development. Hoboken: Wiley; 2007. Novartis Foundation Symposium 284.

Bowmaker JK, Hunt DM. Evolution of vertebrate visual pigments. Curr Biol. 2006;16:R484-9. doi:10.1016/j.cub.2006.06.016.

Bridgham JT, Carroll SM, Thornton JW. Evolution of hormonereceptor complexity by molecular exploitation. Science. 2006;312:97-101. doi:10.1126/science.1123348.

Briscoe AD. Reconstructing the ancestral butterfly eye: focus on the opsins. J Exp Biol. 2008;211:1805-13. doi:10.1242/jeb.013045.

Buschbeck E, Friedrich M. Evolution of insect eyes: tales of ancient heritage, deconstruction, reconstruction, remodeling, and recycling. Evo Edu Outreach. 2008;1:(4). doi:10.1007/s12052-0080086-z.

Cairns-Smith AG. Seven clues to the origin of life. Cambridge: Cambridge University Press; 1985

Chiou TH, Kleinlogel S, Cronin T, Caldwell R, Loeffler B, Siddiqi A, et al. Circular polarization vision in a stomatopod crustacean. Curr Biol. 2008;18:429-34. doi:10.1016/j.cub.2008.02.066.

Chow RL, Altmann CR, Lang RA, Hemmati-Brivanlou A. Pax6 induces ectopic eyes in a vertebrate. Development. 1999;126:4213-22.

Clarkson E, Levi-Setti R, Horvath G. The eyes of trilobites: the oldest preserved visual system. Arthropod Struct Dev. 2006;35:247-59. doi:10.1016/j.asd.2006.08.002

Cleland CE. Historical science, experimental science, and the scientific method. Geology. 2001;29:987-90. doi:10.1130/00917613(2001)029<0987:HSESAT>2.0.CO;2.

Cleland CE. Methodological and epistemic differences between historical science and experimental science. Philos Sci. 2002;69:474-96. doi:10.1086/342455.

Conn HW. The method of evolution. New York: G. P. Putnam's Sons; 1900.

Cronin TW, Porter ML. Exceptional variation on a common theme: the evolution of crustacean compound eyes. Evo Edu Outreach. 2008;1(4). doi:10.1007/s12052-008-0085-0.

Cuthbertson RA, Tomarev SI, Piatigorsky J. Taxon-specific recruitment of enzymes as major soluble proteins in the corneal epithelium of three mammals, chicken, and squid. Proc Natl Acad Sci USA. 1992;89:4004-8. doi:10.1073/pnas.89.9.4004.

Cvekl A, Piatigorsky J. Lens development and crystallin gene expression: many roles for Pax-6. Bioessays. 1996;18:621-30. doi:10.1002/ bies. 950180805 .

Daeschler EB, Shubin NH, Jenkins FA. A Devonian tetrapod-like fish and the evolution of the tetrapod body plan. Nature. 2006;440:75763. doi: $10.1038 /$ nature 04639 .

Darwin C. On the origin of species by means of natural selection, or the preservation of favoured races in the struggle for life. 1st ed. London: Murray; 1859.
Darwin C. The origin of species by means of natural selection, or the preservation of favoured races in the struggle for life. 6th ed. London: Murray; 1872.

Darwin C. The autobiography of Charles Darwin 1809-1882 (Edited by Nora Barlow). London: Collins; 1958.

Dawkins R. The blind watchmaker. New York: Penguin; 1986.

Dawkins R. Climbing mount improbable. New York: W.W. Norton \& Co.; 1996.

Deméré TA, McGowen MR, Berta A, Gatesy J. Morphological and molecular evidence for a stepwise evolutionary transition from teeth to baleen in mysticete whales. Syst Biol. 2008;57:15-37. doi:10.1080/10635150701884632.

de Quieroz A. Do image-forming eyes promote evolutionary diversification? Evolution Int J Org Evolution. 1999;53:1654-64. doi:10. 2307/2640429.

Dial KP. Wing-assisted incline running and the evolution of flight Science. 2003;299:402-4. doi:10.1126/science.1078237.

Draper P. Irreducible complexity and Darwinian gradualism: a reply to Michael J. Behe. Faith Philos. 2002;19:3-21.

Dulai KS, von Dornum M, Mollon JD, Hunt DM. The evolution of trichromatic color vision by opsin gene duplication in New World and Old World primates. Genome Res. 1999;9:629-38.

Ebrey T, Koutalos Y. Vertebrate photoreceptors. Prog Retin Eye Res. 2001;20:49-94. doi:10.1016/S1350-9462(00)00014-8.

Elofsson R. The frontal eyes of crustaceans. Arthropod Struct Dev. 2006;35:275-91. doi:10.1016/j.asd.2006.08.004.

Fernald RD. Eyes: variety, development and evolution. Brain Behav Evol. 2004a;64:141-7. doi:10.1159/000079743.

Fernald RD. Evolving eyes. Int J Dev Biol. 2004b;48:701-5. doi:10 1387/ijdb.041888rf.

Fernald RD. Casting a genetic light on the evolution of eyes. Science. 2006;313:1914-8. doi:10.1126/science.1127889.

Friedman M. The evolutionary origin of flatfish asymmetry. Nature. 2008;454:209-12. doi:10.1038/nature07108.

Gaten E. Optics and phylogeny: is there an insight? The evolution of superposition eyes in the Decapoda (Crustacea). Contrib Zool. 1998;67:223-36.

Gehring WJ. The genetic control of eye development and its implications for the evolution of various eye types. Zoology. 2001;104:171-83. doi:10.1078/0944-2006-00022.

Gehring WJ. Historical perspectives on the development and evolution of eyes and photoreceptors. Int J Dev Biol. 2004;48:707-17. doi:10. 1387/ijdb.041900wg.

Gehring WJ. New perspectives on eye development and the evolution of eyes and photoreceptors. J Hered. 2005;96:171-84. doi:10.1093/ jhered/esi027.

Gehring WJ, Ikeo K. Pax 6: mastering eye morphogenesis and eye evolution. Trends Genet. 1999;15:371-7. doi:10.1016/S0168-95 25(99)01776-X

Gerl EJ, Morris MR. The causes and consequences of color vision. Evo Edu Outreach. 2008;1(4). doi:10.1007/s12052-008-0088-x.

Goldsmith TH. Optimization, constraint, and history in the evolution of eyes. Q Rev Biol. 1990;65:281-322. doi:10.1086/416840.

Gould SJ. The structure of evolutionary theory. Cambridge: Harvard University Press; 2002.

Gould SJ, Lewontin RC. The spandrels of San Marco and the Panglossian paradigm: a critique of the adaptationist programme. Proc R Soc Lond B Biol Sci. 1979;205:581-98.

Gould SJ, Vrba ES. Exaptation - a missing term in the science of form. Paleobiology. 1982;8:4-15.

Gregory TR. Evolutionary trends. Evo Edu Outreach. 2008a;1:25973.

Gregory TR. Evolution as fact, theory, and path. Evo Edu Outreach. 2008b;1:46-52. doi:10.1007/s12052-007-0001-z.

Gregory TR. Understanding evolutionary trees. Evo Edu Outreach. 2008c;1:121-37. doi:10.1007/s12052-008-0035-x. 
Greven H. Comments on the eyes of tardigrades. Arthropod Struct Dev. 2007;36:401-7. doi:10.1016/j.asd.2007.06.003.

Halder G, Callaerts P, Gehring WJ. Induction of ectopic eyes by targeted expression of the eyeless gene in Drosophila. Science. 1995a;267:1788-92. doi:10.1126/science.7892602.

Halder G, Callaerts P, Gehring WJ. New perspectives on eye evolution. Curr Opin Genet Dev. 1995b;5:602-9. doi:10.1016/0959-437X (95)80029-8.

Hall BK. Introduction. In: Hall BK, editor. Homology: the hierarchical basis of comparative biology. New York: Academic Press; 1994. p. 1-19.

Hall BK. Descent with modification: the unity underlying homology and homoplasy as seen through an analysis of development and evolution. Biol Rev Camb Philos Soc. 2003;78:409-33. doi:10.1017/ S1464793102006097.

Hall BK. Homoplasy and homology: dichotomy or continuum? J Hum Evol. 2007;52:473-9. doi:10.1016/j.jhevol.2006.11.010.

Harris WA. Pax-6: where to be conserved is not conservative. Proc Natl Acad Sci USA. 1997;94:2098-100.

Hesse R. Das Sehen der niederen Tiere. Jenna: Fischer; 1908.

Hisatomi O, Tokunaga F. Molecular evolution of proteins involved in vertebrate phototransduction. Comp Biochem Physiol B. 2002; 133:509-22. doi:10.1016/S1096-4959(02)00127-6.

Hodin J. Plasticity and constraints in development and evolution. J Exp Zool (Mol Dev Evol). 2000;288:1-20. doi:10.1002/(SICI) 1097-010X(20000415)288:1<1::AID-JEZ1>3.0.CO;2-7.

Jacob F. Evolution and tinkering. Science. 1977;196:1161-6. doi:10. 1126/science.860134.

Jacob F. The possible and the actual. Seattle: University of Washington Press; 1982.

Jacob F. Complexity and tinkering. Ann N Y Acad Sci. 2001;929:71-3.

Janvier P. Squint of the fossil flatfish. Nature. 2008;454:169-70. doi: $10.1038 / 454169$ a.

Jia S, Omelchenko M, Garland D, Vasiliou V, Kanungo J, Spencer M, et al. Duplicated gelsolin family genes in zebrafish: a novel scinderinlike gene (scinla) encodes the major corneal crystallin. FASEB J. 2007;21:3318-28. doi:10.1096/fj.07-8172com.

Jonasova K, Kozmik Z. Eye evolution: lens and cornea as an upgrade of animal visual system. Semin Cell Dev Biol. 2008;19:71-81. doi:10.1016/j.semcdb.2007.10.005.

Kawamura S, Tachibanaki S. Rod and cone photoreceptors: molecular basis of the difference in their physiology. Comp Biochem Physiol A. 2008;150:369-77. doi:10.1016/j.cbpa.2008.04.600.

Kirschfeld K. The resolution of lens and compound eyes. In: Zettler F, Weiler R, editors. Neural principles in vision. Berlin: Springer; 1976. p. 354-70.

Kolb H. How the retina works. Am Sci. 2003;91:28-35.

Kozmik Z. The role of Pax genes in eye evolution. Brain Res Bull. 2008;75:335-9. doi:10.1016/j.brainresbull.2007.10.046.

Kozmik Z, Ruzickova J, Jonasova K, Matsumoto Y, Vopalensky P, Kozmikova I, et al. Assembly of the cnidarian camera-type eye from vertebrate-like components. Proc Natl Acad Sci U S A. 2008a;105:8989-93. doi:10.1073/pnas.0800388105.

Kozmik Z, Swamynathan SK, Ruzickova J, Jonasova K, Paces V, Vlcek C, et al. Cubozoan crystallins: evidence for convergent evolution of Pax regulatory sequences. Evol Dev. 2008b;10:52-61.

Krishnan K, Kathiresan T, Raman R, Rajini B, Dhople VM, Aggrawal $\mathrm{RK}$, et al. Ubiquitous lens $\alpha$-, $\beta$-, and $\gamma$-crystallins accumulated in anuran cornea as corneal crystallins. J Biol Chem. 2007;282:189539. doi:10.1074/jbc.M609275200.

Kuchiiwa T, Kuchiiwa S, Teshirogi W. Comparative morphological studies on the visual systems in a binocular and multi-ocular species of freshwater planarian. Hydrobiologia. 1991;227:241-9. doi:10. 1007/BF00027608.

Kumar JP. Signalling pathways in Drosophila and vertebrate retinal development. Nat Rev Genet. 2001;2:846-57. doi:10.1038/ 35098564
Kutschera U, Niklas KJ. The modern theory of biological evolution: an expanded synthesis. Naturwissenschaften. 2004;91:255-76. doi:10. 1007/s00114-004-0515-y.

Lamb TD, Collin SP, Pugh EN. Evolution of the vertebrate eye: opsins, photoreceptors, retina and eye cup. Nat Rev Neurosci. 2007;8:960 75. doi:doi:10.1038/nrn2283.

Lamb TD, Pugh EN, Collin SP. The origin of the vertebrate eye. Evo Edu Outreach. 2008;1(4). doi:10.1007/s12052-008-0091-2.

Land MF. The optics of animal eyes. Contemp Phys. 1988;29:435-55. doi:10.1080/00107518808222601.

Land MF. Visual acuity in insects. Annu Rev Entomol. 1997;42:14777. doi:10.1146/annurev.ento.42.1.147.

Land MF, Fernald RD. The evolution of eyes. Annu Rev Neurosci. 1992;15:1-29. doi:10.1146/annurev.ne.15.030192.000245.

Land MF, Nilsson DE. Animal eyes. Oxford: Oxford University Press; 2002.

Larusso ND, Ruttenberg BE, Singh AK, Oakley TH. Type II opsins: evolutionary origin by internal domain duplication? J Mol Evol. 2008;66:417-23. doi:10.1007/s00239-008-9076-6.

Laubichler MD. Tinkering: a conceptual and historical evaluation. In: Bock G, Goode J, editors. Tinkering: the microevolution of development. Chichester: Wiley; 2007. p. 20-34. Novartis Foundation Symposium 284.

Le Page M. Evolution: a guide for the not-yet perplexed. New Sci. 2008;19 April:25-33.

Lynch M. Simple evolutionary pathways to complex proteins. Protein Sci. 2005;14:2217-25. doi:10.1110/ps.041171805.

Lynch M. The evolution of genetic networks by non-adaptive processes. Nat Rev Genet. 2007a;8:803-13. doi:10.1038/nrg2192.

Lynch M. The frailty of adaptive hypotheses for the origins of organismal complexity. Proc Natl Acad Sci USA. 2007b;104(Suppl. 1):8597604. doi:10.1073/pnas.0702207104.

Marden JH, Kramer MG. Surface-skimming stoneflies: a possible intermediate stage in insect flight evolution. Science. 1994;266: 427-30. doi:10.1126/science.266.5184.427.

Marden JH, Thomas MA. Rowing locomotion by a stonefly that possesses the ancestral pterygote condition of co-occurring wings and abdominal gills. Biol J Linn Soc Lond. 2003;79:341-9. doi:10. 1046/j.1095-8312.2003.00192.x.

Marshall J, Cronin TW, Kleinlogel S. Stomatopod eye structure and function: a review. Arthropod Struct Dev. 2007;36:420-48. doi:10. 1016/j.asd.2007.01.006.

Mayer G. Structure and development of onychophoran eyes: what is the ancestral visual organ in arthropods? Arthropod Struct Dev. 2006;35:231-45. doi:10.1016/j.asd.2006.06.003.

McLennan DA. The concept of co-option: why evolution often looks miraculous. Evo Edu Outreach. 2008;1:247-58. doi:10.1007/ s12052-008-0053-8.

Miller KR. Life's grand design. Technol Rev. 1994;97:24-32.

Mivart SG. On the genesis of species. London: MacMillan; 1871.

Müller MCM, Sombke A, Rosenbreg J. The fine structure of the eyes of some bristly millipedes (Penicillata, Diplopoda): additional support for the homology of mandibulate ommatidia. Arthropod Struct Dev. 2007;36:463-76. doi:10.1016/j.asd.2007.09.002.

Newell GE. The eye of Littorina littorea. Proc Zool Soc Lond. 1965; 144:75-86.

Nielsen C, Martinez P. Patterns of gene expression: homology or homocracy? Dev Genes Evol. 2003;213:149-54.

Nilsson DE. Vision optics and evolution. Bioscience. 1989;39:298307. doi:10.2307/1311112.

Nilsson DE. Eye evolution: a question of genetic promiscuity. Curr Opin Neurobiol. 2004;14:407-14. doi:10.1016/j.conb.2004. 07.004 .

Nilsson DE, Kelber A. A functional analysis of compound eye evolution. Arthropod Struct Dev. 2007;36:373-85. doi:10.1016/j. asd.2007.07.003. 
Nilsson DE, Pelger S. A pessimistic estimate of the time required for an eye to evolve. Proc R Soc Lond B Biol Sci. 1994;256:53-8. doi:10.1098/rspb.1994.0048.

Nilsson DE, Gislen L, Coates MM, Skogh C, Garm A. Advanced optics in a jellyfish eye. Nature. 2005;435:201-5. doi:10.1038/ nature 03484

Nordström K, Wallén R, Seymour J, Nilsson D. A simple visual system without neurons in jellyfish larvae. Proc R Soc Lond B Biol Sci. 2003;270:2349-54. doi:10.1098/rspb.2003.2504.

Novella S. Suboptimal optics: vision problems as scars of evolutionary history. Evo Edu Outreach. 2008;1(4). doi:10.1007/s12052008-0092-1.

Novembre J, Pritchard JK, Coop G. Adaptive drool in the gene pool. Nat Genet. 2007;39:1188-90. doi:10.1038/ng1007-1188.

Oakley TH. The eye as a replicating and diverging, modular developmental unit. Trends Ecol Evol. 2003;18:623-7. doi:10.1016/j. tree.2003.09.005.

Oakley TH. Today's multiple choice exam: (a) gene duplication; (b) structural mutation; (c) co-option; (d) regulatory mutation; (e) all of the above. Evol Dev. 2007;9:523-4.

Oakley TH, Cunningham CW. Molecular phylogenetic evidence for the independent evolutionary origin of an arthropod compound eye. Proc Natl Acad Sci U S A. 2002;99:1426-30. doi:10.1073/pnas. 032483599

Oakley TH, Pankey MS. Opening the "black box": the genetic and biochemical basis of eye evolution. Evo Edu Outreach. 2008;1 (4). doi:10.1007/s12052-008-0090-3.

Oakley TH, Østman B, Wilson ACV. Repression and loss of gene expression outpaces activation and gain in recently duplicated fly genes. Proc Natl Acad Sci U S A. 2006;103:11637-41. doi:10.1073/ pnas.0600750103.

Oakley TH, Plachetzki DC, Rivera AS. Furcation, field-splitting, and the evolutionary origins of novelty in arthropod photoreceptors. Arthropod Struct Dev. 2007;36:386-400. doi:10.1016/j. asd.2007.08.002.

Ohno S. Evolution by gene duplication. New York: Springer; 1970.

Okano T, Kojima D, Fukada Y, Shichida Y, Yoshizawa T. Primary structures of chicken cone visual pigments: vertebrate rhodopsins have evolved out of cone visual pigments. Proc Natl Acad Sci USA. 1992;89:5932-6. doi:10.1073/pnas.89. 13.5932.

Osorio D. Eye evolution: Darwin's shudder stilled. Trends Ecol Evol. 1994;9:241-2. doi:10.1016/0169-5347(94)90286-0.

Paley W. Natural theology, or evidences of the existence and attributes of the deity, collected from the appearances of nature. London: Glazier; 1802.

Pallen MJ, Matzke NJ. From The origin of species to the origin of bacterial flagella. Nat Rev Microbiol. 2006;4:784-90. doi:10.1038/ nrmicro1493.

Panchen A. Richard Owen and the concept of homology. In: Hall BK, editor. Homology: the hierarchical basis of comparative biology. New York: Academic; 1994. p. 21-62.

Panchen A. Homology - history of a concept. In: Bock GR, Cardew G, editors. Homology. Chichester: Wiley; 1999. p. 5-23. Novartis Foundation Symposium 222.

Perry GH, Dominy NJ, Claw KG, Lee AS, Fiegler H, Redon R, et al. Diet and the evolution of human amylase gene copy number variation. Nat Genet. 2007;39:1256-60. doi:10.1038/ng2123.

Piatigorsky J. Multifunctional lens crystallins and corneal enzymes: more than meets the eye. Ann N Y Acad Sci. 1998;842:7-15. doi:10.1111/j.1749-6632.1998.tb09626.x.

Piatigorsky J. Gene sharing and evolution. Cambridge: Harvard University Press; 2007.

Piatigorsky J. A genetic perspective on eye evolution: gene sharing, convergence and parallelism. Evo Edu Outreach. 2008;1(4). doi:10.1007/s12052-008-0077-0.
Plachetzki DC, Oakley TH. Key transitions during the evolution of animal phototransduction: novelty, "tree-thinking," co-option, and co-duplication. Integr Comp Biol. 2007;47:759-69. doi:10.1093/icb/icm050.

Plachetzki DC, Serb JM, Oakley TH. New insights into the evolutionary history of photoreceptor cells. Trends Ecol Evol. 2005;20:465-7. doi:10.1016/j.tree.2005.07.001.

Purschke G, Arendt D, Hausen H, Muller MCM. Photoreceptor cells and eyes in Annelida. Arthropod Struct Dev. 2006;35:211-30. doi:10.1016/j.asd.2006.07.005.

Quiring R, Waldorf U, Kloter U, Gehring WJ. Homology of the eyeless gene of Drosophila to the Small eye gene in mice and Aniridia in humans. Science. 1994;265:785-9. doi:10.1126 science.7914031.

Ratnoff OD, Margolius A. Hageman trait: an asymptomatic disorder of blood coagulation. Trans Assoc Am Physicians. 1955;68:149-54.

Reimann A, Richter S. The nauplius eye complex in 'conchostracans' (Crustacea, Branchiopoda: Laevicaudata, Spinicaudata, Cyclestherida) and its phylogenetic implications. Arthropod Struct Dev. 2007;36:408-19. doi:10.1016/j.asd.2007.08.005.

Rohde K, Watson NA. Ultrastructure of pigmented photoreceptors of larval Multicotyle purvisi (Trematoda, Aspidogastrea). Parasitol Res. 1991;77:485-90. doi:10.1007/BF00928415.

Rutishauser R, Moline P. Evo-devo and the search for homology ("sameness") in biological systems. Theory Biosci. 2005;124:213-41.

Salvini-Plawen LV, Mayr E. On the evolution of photoreceptors and eyes. Evol Biol. 1977;10:207-63.

Santillo S, Orlando P, De Petrocellis L, Cristino L, Guglielmotti V, Musio C. Evolving visual pigments: hints from the opsin-based proteins in a phylogenetically old "eyeless" invertebrate. Biosystems. 2006;86:3-17. doi:10.1016/j.biosystems.2006.03.008.

Schneider TD. Evolution of biological information. Nucleic Acids Res. 2000;28:2794-9. doi:10.1093/nar/28.14.2794.

Scott EC, Matzke NJ. Biological design in science classrooms. Proc Natl Acad Sci U S A. 2007;104:8669-76. doi:10.1073/pnas. 0701505104

Serb JM, Eernisse DJ. Charting evolution's trajectory: using molluscan eye diversity to understand parallel and convergent evolution. Evo Edu Outreach. 2008;1(4). doi:10.1007/s12052-008-0084-1.

Shimeld SM, Purkiss AG, Dirks RPH, Bateman OA, Slingsby C, Lubsen $\mathrm{NH}$. Urochordate $\beta \gamma$-crystallin and the evolutionary origin of the vertebrate eye lens. Curr Biol. 2005;15:1684-9. doi:10.1016/j.cub. 2005.08.046.

Shubin NH. Your inner fish. New York: Pantheon; 2007.

Shubin NH, Marshall CR. Fossils, genes, and the origin of novelty. Paleobiology. 2000;26(Suppl.):324-40. doi:10.1666/0094-8373 (2000)26[324:FGATOO]2.0.CO;2.

Shubin NH, Daeschler EB, Jenkins FA. The pectoral fin of Tiktaalik roseae and the origin of the tetrapod limb. Nature. 2006;440:764 71. doi: 10.1038 /nature 04637 .

Spady TC, Parry JWL, Robinson PR, Hunt DM, Bowmaker JK, Carleton KL. Evolution of the cichlid visual palette through ontogenetic subfunctionalization of the opsin gene arrays. Mol Biol Evol. 2006;23:1538-47. doi:10.1093/molbev/ms1014.

Spudich JL, Yang CS, Jung KH, Spudich EN. Retinylidene proteins: structures and functions from Archaea to humans. Annu Rev Cell Dev Biol. 2000;16:365-95. doi:10.1146/annurev.cellbio.16.1.365.

Sweeney AM, Des Marais DL, Ban YEA, Johnsen S. Evolution of graded refractive index in squid lenses. J R Soc Interface. 2007:4:685-98. doi:10.1098/rsif.2006.0210.

Taylor JS, Raes J. Duplication and divergence: the evolution of new genes and old ideas. Annu Rev Genet. 2004:38:615-43. doi:10. 1146/annurev.genet.38.072902.092831.

Terakita A. The opsins. Genome Biol. 2005;6:213. doi:10.1186/gb2005-6-3-213.

Thanukos A. Bringing homologies into focus. Evo Edu Outreach. 2008;1(4). doi:10.1007/s12052-008-0080-5. 
Thornhill RH, Ussery DW. A classification of possible routes of Darwinian evolution. J Theor Biol. 2000;203:111-6. doi:10.1006/ jtbi.2000.1070.

Tomarev SI, Piatigorsky J. Lens crystallins of invertebrates: diversity and recruitment from detoxification enzymes and novel proteins. Eur $\mathrm{J}$ Biochem. 1996;235:449-65. doi:10.1111/j.1432-1033.1996.00449.x.

Treisman JE. How to make an eye. Development. 2004;131:3823-7. doi: $10.1242 /$ dev.01319.

True JR, Carroll SB. Gene co-option in physiological and morphological evolution. Annu Rev Cell Dev Biol. 2002;18:53-80. doi:10.1146/ annurev.cellbio.18.020402.140619.

Van Gelder RN. Non-visual photoreception: sensing light without sight. Curr Biol. 2007;18:R38-9. doi:10.1016/j.cub.2007.11.027.

Wagner GP. The developmental genetics of homology. Nat Rev Genet. 2007;8:473-9. doi:10.1038/nrg2099.

Ward A, Liu J, Feng Z, Xu XZS. Light-sensitive neurons and channels mediate phototaxis in C. elegans. Nat Neurosci. 2008;11:916-22. doi:10.1038/nn.2155.

Wehner R. Brainless eyes. Nature. 2005;435:157-8. doi:10.1038/435157a.

Young JZ. A model of the brain. Oxford: Oxford University Press; 1964.

Zaidi FH, Hull JT, Peirson SN, Wulff K, Aeschbach D, Gooley JJ, et al. Short-wavelength light sensitivity of circadian, pupillary, and visual awareness in humans lacking an outer retina. Curr Biol. 2007;17:2122-8. doi:10.1016/j.cub.2007.11.034.

Zhou L, Mitra R, Atkinson PW, Burgess Hickman A, Dyda F, Craig NL. Transposition of $h A T$ elements links transposable elements and V(D)J recombination. Nature. 2004;432:995-1001. doi:10. 1038/nature03157.
Zimmer C. The evolution of extraordinary eyes: the cases of flounders and stalk-eyed flies. Evo Edu Outreach. 2008;1:(4). doi:10.1007/ s12052-008-0089-9.

\section{Online Resources}

In the Light of Evolution I: Adaptation and Complex Design (Arthur M. Sackler Colloquium of the National Academy of Sciences) http://www.nasonline.org/adaptation_and_complex_design

Understanding Evolution http://evolution.berkeley.edu/evolibrary/article/eyes 01 http://evolution.berkeley.edu/evolibrary/article/_0_0/evo_53 http://evolution.berkeley.edu/evosite/evo101/IIIENaturalSelection. shtml

Evolution: 24 Myths and Misconceptions (New Scientist) http://www.newscientist.com/channel/life/dn 13620 ? DCMP $=$ NLC-nletter\&nsref $=\operatorname{dn} 13620$

PBS Evolution http://www.pbs.org/wgbh/evolution/library/01/1/1_011_01.html

Animation of vertebrate eye development (Lamb et al. 2007) http://www.nature.com/nrn/journal/v8/n12/suppinfo/nrn2283.html

Videos of eyeless nematode detecting light (Ward et al. 2008) http://www.nature.com/neuro/journal/v11/n8/suppinfo/ nn.2155 S1.html 